Florida International University FIU Digital Commons

$11-3-2016$

\title{
Cognitive Beharioal-Therapy for Child Anxiety: Long-term Follow-up and Predictors of Long-term Outcomes
}

Cristina T. del Busto

Florida International University, cdelbust@fiu.edu

DOI: $10.25148 /$ etd.FIDC001199

Follow this and additional works at: https:// digitalcommons.fiu.edu/etd

Part of the Child Psychology Commons, and the Clinical Psychology Commons

\section{Recommended Citation}

del Busto, Cristina T., "Cognitive Beharioal-Therapy for Child Anxiety: Long-term Follow-up and Predictors of Long-term Outcomes" (2016). FIU Electronic Theses and Dissertations. 3034.

https://digitalcommons.fiu.edu/etd/3034 


\title{
FLORIDA INTERNATIONAL UNIVERSITY
}

Miami, Florida

\section{COGNITIVE-BEHAVIORAL THERAPY FOR CHILD ANXIETY: LONG-TERM FOLLOW-UP AND PREDICTORS OF LONG-TERM OUTCOMES}

\author{
A dissertation submitted in partial fulfillment of the \\ requirements for the degree of \\ DOCTOR OF PHILOSOPHY \\ in \\ PSYCHOLOGY \\ by
}

Cristina T. del Busto

2016 


\section{To: Dean Michael R. Heithaus}

\section{College of Arts, Sciences, and Education}

This dissertation, written by Cristina T. del Busto, and entitled CBT for Child Anxiety: Long-term Follow-up and Predictors of Long-term Outcomes, having been approved in respect to style and intellectual content, is referred to you for judgment.

We have read this dissertation and recommend that it be approved.

Dionne Stephens

Shannon Pruden

Charles Bleiker

Wendy K. Silverman

Jeremy W. Pettit, Major Professor

Date of Defense: November 3, 2016

The dissertation of Cristina T. del Busto is approved.

Dean Michael R. Heithaus College of Arts, Sciences and Education

Andrés G. Gil

Vice President for Research and Economic Development and Dean of the University Graduate School

Florida International University, 2016 
(C) Copyright 2016 by Cristina T. del Busto

All rights reserved. 


\section{DEDICATION}

This dissertation is dedicated to my family; without whom this would not have been possible. I especially would like to recognize my parents who taught me to believe in myself and showered me with unconditional love and support throughout my life. Thank you for always being there for me and for the many sacrifices you have made for our family. Everything we have been able to do and accomplish has been through the love and support you have given us. Thank you for teaching us the importance of family and for instilling in us our strong cultural values. I am the luckiest to be your daughter.

To my little brother and little sister, my first forever friends who continue to inspire me every day. You have grown up to be amazing people. I am so proud of your determination and perseverance in life.

To my husband. Thank you for your love and support, and for eating all those t.v. dinners uncomplainingly while I finished my studies. You are an incredible life partner and I am truly blessed to have you by my side. 


\section{ACKNOWLEDGMENTS}

I am fortunate that I have come across so many wonderful people that have walked alongside me throughout this journey and without whom I would not have been able to reach this milestone in my career. I would like to first acknowledge and thank Dr. Janet Kistner and Dr. Cristina Lopez for giving me my first opportunity as an undergraduate student so many years ago. Thank you for believing in me and for your encouragement to pursue my education.

Wendy and Jeremy, I thank you for spending the next six years guiding me along the way. Thank you for the opportunity to learn from you and for your support each step of the way. Your dedication to my learning and education has left a lasting influence in my personal and professional development, and for that, I humbly thank you.

I would also like to acknowledge the current and former members of the Child Anxiety and Phobia Program, whose passion for working with children and families have made it possible to help hundreds of families over the last twenty years. I am incredibly proud to have had the opportunity to be a small part of CAPP for the last six years. In particular, I would like to thank Yasmin Rey, Kristin Nichols-Lopez, Carla Marin, and Yesenia Rodriguez. Thank you for being a part of this chapter in my life, and for moving past being work colleagues and becoming my friends.

I would also like to thank the many families whom I personally worked with for allowing me to learn with them and be a part of their families' journey. 
Lastly, I would like to acknowledge and thank my committee members, Drs. Dionne Stephens, Shannon Pruden, Charles Bleiker, Wendy Silverman, and Jeremy Pettit. Thank you for your commitment and support throughout this process. 


\section{ABSTRACT OF THE DISSERTATION \\ CBT FOR CHILD ANXIETY: \\ LONG-TERM FOLLOW-UP AND PREDICTORS OF LONG-TERM OUTCOMES \\ by}

Cristina T. del Busto

Florida International University, 2016

Miami, Florida

\section{Professor Jeremy W. Pettit, Major Professor}

Anxiety and its disorders are highly prevalent in childhood and adolescence, and are associated with impairment in social and academic functioning. Empirical evidence has accumulated demonstrating the efficacy of cognitive-behavioral therapy (CBT) for youth anxiety disorders delivered in individual, group, and parent formats. This dissertation study compared two of these formats, a youth only individual format, and two types of parental involvement formats to answer questions related to the long-term diagnostic outcomes and psychosocial functioning outcomes of youth who receive CBT for anxiety disorders. Specifically, this dissertation sought to compare individual and parent involvement to determine whether targeting parenting behaviors associated with youth anxiety produces significantly lower levels of psychopathology at a follow-up evaluation. The sample consisted of 173 youth and their parents who completed a followup evaluation one to seven years following treatment for youth anxiety disorders.

Research questions were examined using regression analyses within a structural equation modeling framework. Results indicate that youth who demonstrated positive treatment gains at post treatment continued to maintain these gains at the long-term follow-up 
period one to seven years following treatment. Treatment condition significantly predicted ratings of youth anxiety symptoms at follow-up according to parent ratings, indicating lower youth anxiety symptom ratings for participants in the parent-involved conditions compared to participants in the youth only condition. Youth in the parentinvolved conditions were also rated higher on social functioning at follow-up on the parent report, as compared to youth in the individual treatment condition. The study findings are discussed in terms of treatment design and clinical implications for the treatment of youth anxiety and its disorders. 
CHAPTER

PAGE

I. INTRODUCTION --- 1

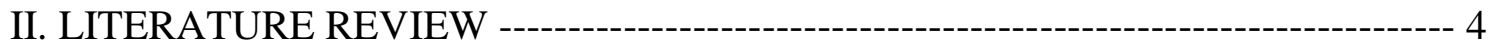

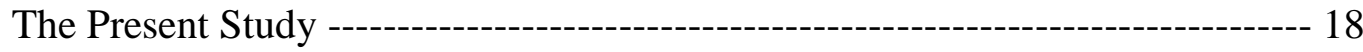

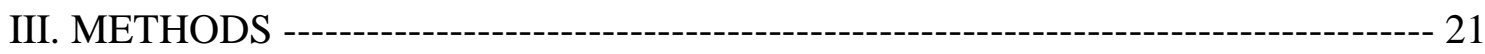

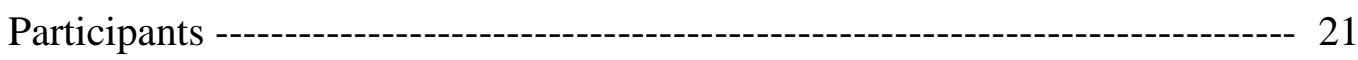

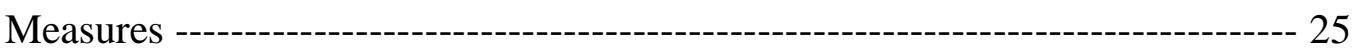

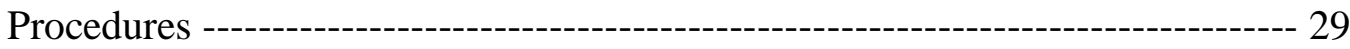

IV. RESULTS --- 31

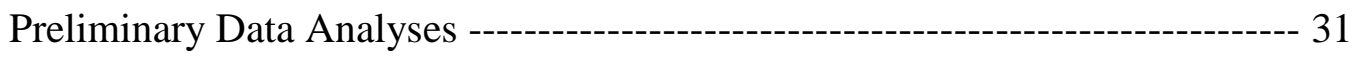

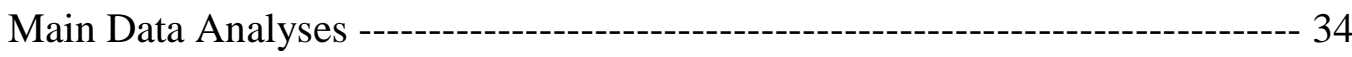

Ancillary Data Analyses ---_-

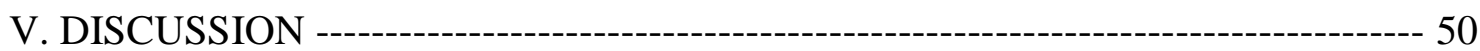

Clinical Implications ------------------------------------------------- 54

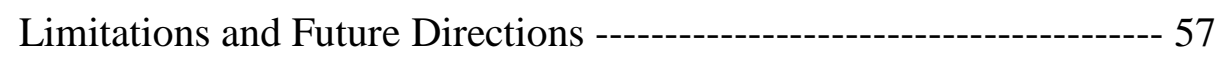

LIST OF REFERENCES ---_- 83

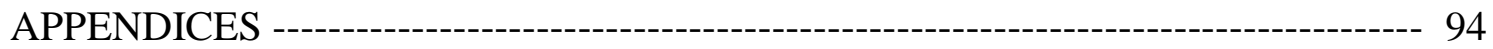

VITA --- 


\section{LIST OF TABLES}

TABLE

PAGE

One. Demographic and Diagnostic Information by Treatment Condition

Two. Mean (Standard Deviations) for Youth and Parent Completed

Outcome Measures for Full Treatment Completer Sample

Three. Mean (Standard Deviations) for Youth and Parent Completed

Outcome Measures

Four. Parameter Estimates and Confidence Intervals for Binary

Logistic Regression Analyses for Categorical Outcomes by Treatment Condition ----64

Five. Parameter Estimates and Confidence Intervals for Binary

Logistic Regression Analyses for Categorical Outcomes by Parenting Condition -----65

Six. Summary of Multiple Regression Analyses for Outcome Variables

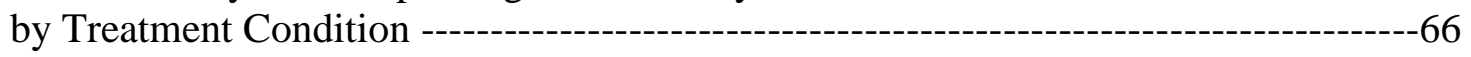

Seven. Summary of Multiple Regression Analyses for Outcome Variables

by Parent Condition

Eight. Unstandardized Path Coefficients and 95\% Confidence Intervals

for Child Academic Functioning Model

Nine. Unstandardized Path Coefficients and 95\% Confidence Intervals

for Parent Academic Functioning Model

Ten. Unstandardized Path Coefficients and 95\% Confidence Intervals

for Child Social Functioning Model $-70$

Eleven. Unstandardized Path Coefficients and 95\% Confidence Intervals

for Parent Social Functioning Model $-71$ 


\section{LIST OF FIGURES}

FIGURE

PAGE

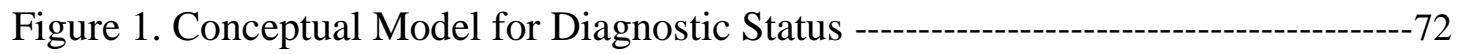

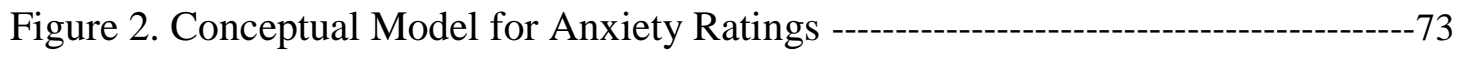

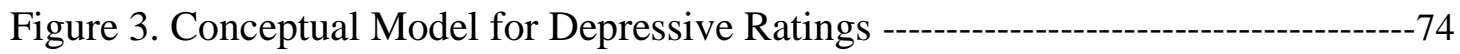

Figure 4. Conceptual Model for Academic Functioning -------------------------------------75

Figure 5. Conceptual Model for Social Functioning -----------------------------------------76

Figure 6. Conceptual Model for Academic Functioning Lagged Effects ----------------77

Figure 7. Conceptual Model for Social Functioning Lagged Effects ---------------------78

Figure 8. Academic Functioning Lagged Effects, Youth Model --------------------------79

Figure 9. Academic Functioning Lagged Effects, Parent Model --------------------------80

Figure 10. Social Functioning Lagged Effects, Youth Model -----------------------------81

Figure 11. Social Functioning Lagged Effects, Parent Model ----------------------------82 


\section{ABBREVIATIONS AND ACRONYMS}

\begin{tabular}{|c|c|}
\hline ADHD & Attention Deficit Hyperactivity Disorder \\
\hline ADIS:IV-C/P & $\begin{array}{l}\text { Anxiety Disorders Interview Schedule for DSM-IV: Child } \\
\text { and Parent Versions }\end{array}$ \\
\hline CAPP & Child Anxiety and Phobia Program \\
\hline CBCL & Child Behavior Checklist \\
\hline $\mathrm{CBT}$ & Cognitive-behavioral Therapy \\
\hline $\mathrm{CBT}+\mathrm{P}$ & CBT with parental involvement \\
\hline CDI & Children's Depression Inventory \\
\hline CFI & Comparative Fit Index \\
\hline DSM-IV-TR & $\begin{array}{l}\text { Diagnostic and Statistical Manual of Mental Disorders, } \\
\text { Fourth Edition, Text Revision }\end{array}$ \\
\hline FIML & Full Information Maximum Likelihood \\
\hline ICBT & Individual CBT treatment approach \\
\hline GCBT & Group CBT treatment approach \\
\hline LTFU & Long-term Follow-up \\
\hline MDD & Major Depressive Disorder \\
\hline PDD & Pervasive Developmental Disorder \\
\hline RCMAS & Revised Children's Manifest Anxiety Scale \\
\hline RCMAS-P & Revised Children's Manifest Anxiety Scale, Parent Version \\
\hline $\mathrm{RCT}$ & Randomized Control Trial \\
\hline RFST & Reinforcement Skills Training \\
\hline RLST & Relationship Skills Training \\
\hline
\end{tabular}


RMSEA

SEM

Standardized RMR

SUD

TAU

TLI
Root Mean Square Error of Approximation

Structural Equation Modeling

The Standardized Root Mean Square Residual

Substance Use Disorders

Treatment as usual

Tucker-Lewis Index 


\section{CHAPTER I}

\section{INTRODUCTION}

Epidemiological studies have shown anxiety disorders are among the most common, if not the most common, psychiatric disorders reported in children and adolescents (e.g., Costello, Egger, Copeland, Erkanli, \& Angold, 2011) and are associated with impairment in social functioning and academic functioning (e.g., Van Ameringen, Mancini, \& Farvolden, 2003). (Please note: Unless when referring to a specific developmental stage, henceforth, children and adolescents are referred to as "youth"). Anxiety disorders in youth also are associated with high direct medical expenses and related impairments with estimated costs of $\$ 33.71$ billion in 2013 (e.g. Shirneshan et al., 2013). Previous studies have provided substantial evidence that anxiety disorders typically do not remit on their own (e.g., Bittner et al., 2007; Lewinsohn, HolmDenoma, Small, Seeley, \& Joiner, 2008; Pine et al., 1998), and have further shown that the developmental course of untreated anxiety disorders leads to poor mental health outcomes including the onset of other anxiety disorders, major depressive disorder (MDD) and suicide-related behaviors, and substance abuse (e.g., Buckner et al., 2008; Buckner \& Schmidt, 2009; Hill, Castellanos, \& Pettit, 2011; Mathew, Pettit, Lewinsohn, Seeley, \& Roberts, 2011).

Cognitive Behavioral Therapy as an Efficacious Treatment for Youth Anxiety

Over the past 15-20 years, empirical evidence has accumulated demonstrating the efficacy of cognitive-behavioral therapy (CBT) for youth anxiety disorders (see Silverman, Pina, \& Viswesvaran, 2008 for a review). Initially examined using an individual treatment approach for youth (ICBT) (Kendall, 1994; Kendall et al., 1997), 
CBT has since been evaluated in other formats, including group CBT (GCBT) (Barrett, 1998; Beidel, Turner, \& Morris, 2000; Silverman et al., 1999) and parent or family involved CBT (FCBT/CBT+P) (Barrett, Dadds, \& Rapee, 1996).

Cognitive Behavioral Therapy (CBT) for youth anxiety focuses on cognitive and behavioral strategies to reduce anxiety including a) psychoeducation about anxiety and its disorders, b) graded exposure to feared stimuli, c) cognitive restructuring and developing coping-focused thinking strategies, d) relaxation training for somatic symptoms, and e) relapse prevention. In total, over 30 randomized controlled trials support the short-term efficacy of CBT for youth anxiety (see Silverman, Pina, \& Viswesvaran, 2008), meaning reductions in youth anxiety symptoms and related impairment are found at the end of treatment. In a review of ten randomized controlled trials, Cartwright-Hatton and colleagues (2004) reported a pooled estimate of about $60 \%$ primary targeted anxiety disorder remission rate following completion of CBT for youth anxiety, meaning that approximately $60 \%$ of youth no longer met diagnostic criteria for the primary anxiety disorder diagnosis at the end of treatment. Further, meta-analytic reviews provide documentation of substantial levels of anxiety symptom reduction and confirm comparable rates of diagnostic remission following the completion of CBT, $57 \%-62.4 \%$ for CBT with parental involvement and 50\%-60.2\% for ICBT or limited parental involvement (Manassis et al., 2014; Thulin, Svirsky, Serlachius, Andersson, Ost, 2014).

In addition to diagnostic recovery and anxiety symptom level outcomes, studies of CBT for youth anxiety have begun to report on other areas of related impairment, including academic functioning (e.g., Nail et al., 2015) and social functioning (e.g., Beidel, Turner, \&Morris, 2000; Settipanni \& Kendall, 2013). These studies have 
documented that CBT for youth anxiety leads to significant improvement in academic and social functioning by the end of treatment, and the importance of social functioning for treatment outcome (Settipanni et al., 2013). Thus, a large evidence base supports the efficacy of CBT for reducing youth anxiety and its disorders and related impairments in academic and social functioning immediately following treatment.

\section{Long-term Outcomes of CBT for Youth Anxiety}

In contrast to the large evidence base supporting the short-term efficacy of CBT for youth anxiety disorders, a smaller evidence base supports the long-term efficacy of CBT for youth anxiety. The purpose of this dissertation project is to add to this small evidence base by evaluating long-term diagnostic outcomes and psychosocial functioning outcomes among youth who received CBT for anxiety disorders. In the following chapter, I review all published studies that have evaluated long-term diagnostic and psychosocial outcomes of CBT for youth anxiety disorders. I then present the research aims and hypotheses of the present dissertation project. 


\section{CHAPTER II}

\section{LITERATURE REVIEW}

Twelve published studies have examined long-term outcomes of CBT for youth anxiety. Of these, six long-term follow-up studies examined youth CBT delivered in individual (ICBT) or group (GCBT) formats, and one long-term follow-up study examined ICBT, sertraline, or combination treatment (ICBT + sertraline). The remaining long-term follow-up studies examined parent-involved CBT. I review each of these 12 long-term follow-up studies with a focus on anxiety disorder diagnostic recovery rates and levels of anxiety symptom severity at the follow-up evaluations.

\section{Primary Anxiety Outcomes}

In a study of 47 children ages 9-13 (48\% female), Kendall (1994) examined a 16session ICBT protocol for the treatment of anxiety disorders in youth. At the post treatment evaluation, $64 \%$ of participants did not meet diagnostic criteria for an anxiety disorder, although it was not clear whether the diagnostic recovery rate was for only the primary anxiety disorder or any anxiety disorder. At the follow-up evaluation which included 36 youth ages 11-18 from the original sample of 47, Kendall and SouthamGerow (1996) reported a diagnostic recovery rate for primary anxiety disorder ranging between $87-94 \%$ over a two to five year follow-up period. Ratings on youth and parent completed measures also showed maintenance of treatment gains on ratings of anxiety symptoms at the follow-up evaluation.

In a study of 96 children ages 9-13 (38\% female), Kendall et al. (1997) examined a 16-session ICBT protocol for the treatment of anxiety disorders in youth. At the post treatment evaluation, $71 \%$ and $89 \%$ of participants did not meet diagnostic criteria for 
primary anxiety disorder, on the basis of parent and child reports, respectively. At a follow-up evaluation which included 86 youth ages 15-22 from the original sample of 96, Kendall, Safford, Flannery-Schroeder, and Webb (2004) reported a diagnostic recovery rate for primary anxiety disorder between $92-96 \%$ over a five to nine year follow-up period. Ratings on youth and parent completed measures also showed maintenance of treatment gains on ratings of anxiety symptoms at the follow-up evaluation.

Benjamin, Harrison, Settipani, Brodman, and Kendall (2013) extended the followup period of the Kendall et al. (1997) treatment sample and added participants from a separate Randomized Control Trial (RCT) conducted in 2008 (Kendall, Hudson, Gosch, Flannery-Schroeder, \& Suveg, 2008) to examine long term outcomes 7 to 19 years after completing treatment. Specifically, Benjamin et al. (2013) compared youth who had successfully been treated (defined as having no anxiety diagnosis at post) with youth who still had an anxiety disorder at post. At the follow-up evaluation which included 66 individuals ages 18-32 from the original combined samples of 150 youth, Benjamin et al. (2013) reported a diagnostic recovery rate of 56\% for any anxiety disorder diagnosis during a 7 to 19 year follow-up period. Participants' ratings of symptoms of anxiety also showed maintenance of treatment gains at the follow-up evaluation. There were no significant differences found at the follow-up evaluation between individuals who had a successful treatment response at post treatment and those who did not.

In a study of 56 youth ages 6 to 16 (39\% female) assigned to either GCBT or waitlist control (Silverman, Kurtines, Ginsburg, Weems, White Lumpkin, \& Hicks Carmichael, 1999), Silverman and colleagues examined CBT in group format for the treatment of anxiety disorders in youth. At the post treatment evaluation $64 \%$ of 
participants did not meet diagnostic criteria for primary anxiety disorder using parent and youth report combined. In a separate study of 104 youth ages 6 to 16 (48\% female), Silverman, Kurtines, Ginsburg, Weems, Rabian, and Serafini, (1999) examined CBT with contingency management or CBT with self-control relative to a non-specific treatment focused on education support for youth with anxiety disorders. At the post treatment evaluation, $55-88 \%$ of participants did not meet diagnostic criteria for primary targeted anxiety disorder determined by parent and youth report combined. At a follow-up evaluation which included 67 youth ages 16-26 from the two original study samples of 160 combined, Saavedra, Silverman, Morgan-Lopez, and Kurtines (2010) reported a diagnostic recovery rate of $92.5 \%$ for targeted anxiety disorder and $86.5 \%$ for any anxiety disorder over an 8 to 13 year follow-up period. Ratings on youth and parent completed measures also showed maintenance of treatment gains on ratings of anxiety symptoms at follow-up. There were no significant differences found at the follow-up evaluation in diagnostic recovery rates or anxiety symptom levels between individuals who had completed ICBT and individuals who had completed GCBT.

In a study of 67 children ages 8-12 (60\% female), Beidel, et al. (2000) examined a 24-session combination of ICBT and GCBT protocol for the treatment of social phobia in youth (SET-C) against an active non-specific treatment that focused on study skills. At the post treatment evaluation, Beidel et al. (2000) reported that $67 \%$ of participants in the SET-C condition did not meet diagnostic criteria for social phobia. At a follow-up evaluation which included 29 youth ages 11-18 from the original active treatment sample of 36 participants, Beidel, Turner, Young, and Paulson (2005) found a 72\% diagnostic recovery rate for social phobia at the three year follow-up period. Beidel, Turner, and 
Young (2006) subsequently extended the follow-up period to examine outcomes 5 years post treatment in 31 individuals ages 13-20 from the original active treatment sample of 36 participants, and found an $80 \%$ diagnostic recovery rate for social phobia at the five year follow-up period. Ratings on youth and parent completed measures also showed maintenance of treatment gains on ratings of anxiety symptoms at the 3 and 5 year follow-up periods.

In a study of 488 youth ages 7-17 (50\% female), Walkup and colleagues (2008) examined a 12-week protocol that included a therapy condition that was either ICBT, medication condition (sertraline), combined treatment condition (CBT + sertraline), or pill placebo condition for the treatment of anxiety disorders in youth. At the post treatment evaluation, Ginsburg et al. (2011) reported that $20 \%$ to $68 \%$ of participants did not meet diagnostic criteria for primary anxiety disorder using parent and child reports, respectively, with higher rates of remission in the combined treatment $(\mathrm{CBT}+$ sertraline) compared to the other active treatment conditions. Specifically for the CBT condition, $46.2 \%$ of participants did not meet criteria for their primary anxiety disorder at post treatment. At a follow-up evaluation which included 288 individuals ages 11-26 who had received active treatment in the original study (i.e., ICBT, sertraline, or combination), Ginsburg and colleagues (2014) found a primary anxiety disorder diagnostic recovery rate of $46.5 \%$ over a 4 to 10 year follow-up period. Specifically for the CBT condition, 45.8\% of participants did not meet criteria for their primary anxiety disorder at the follow-up. Ginsburg et al. (2014) did not report on parent or youth ratings of youth anxiety symptoms at the follow-up evaluation. 


\section{Other Diagnostic Outcomes}

Only four of the seven long-term follow-up studies reviewed above examined other diagnostic outcomes besides anxiety disorder recovery rates. Kendall et al. (2004) found that $23-33 \%$ of the sample met diagnostic criteria for Major Depressive Disorder (MDD) or Dysthymia at some point during the follow-up period, and $9 \%$ met diagnostic criteria for a Substance Use Disorder (SUD) at follow-up evaluation 5 to 9 years post treatment. Ratings on a youth completed measure also showed maintenance of treatment gains on ratings of depressive symptoms at the follow-up period (even though depression was not targeted in treatment). Beidel and colleagues (2006) found that $12 \%$ of the sample who had completed GCBT were above a clinical cutoff for depressive symptoms at a follow up evaluation five years post treatment, and none of the participants reported any use of alcohol or illicit drug during the follow-up period. Saavedra et al. (2010) reported that $9 \%$ of the sample at follow-up who had completed either CBT or GCBT met diagnostic criteria for MDD, 5\% met diagnostic criteria for Dysthymia, and $20 \%$ met diagnostic criteria for SUD at a follow-up evaluation 8 to 13 years post treatment.

Ratings on a youth completed measure also showed maintenance of treatment gains on ratings of depressive symptoms at a follow-up period (even though depression was not targeted in treatment). Benjamin et al. (2013) reported that $27 \%$ of their sample at follow-up who had completed ICBT met diagnostic criteria for MDD, 3\% met diagnostic criteria for Dysthymia, and $42 \%$ met diagnostic criteria for one or more SUD at a followup evaluation 7 to 19 years post treatment. Ratings on a youth completed measure also showed maintenance of treatment gains on ratings of depressive symptoms at a follow-up period (even though depression was not targeted in treatment). 
Overall, these studies have been important in demonstrating that the majority of youth who receive CBT for anxiety disorders continue to maintain treatment gains up to 19 years post treatment. A subset of these studies also has demonstrated secondary gains in low rates of mood disorders and substance use disorders. In spite of these positive long-term findings, there still is room for improvement in diagnostic outcomes and there are still unaddressed issues related to the long-term outcomes of CBT for youth anxiety disorders. Specifically, very little is known about the influence of parent involvement in youth CBT on long-term outcomes or the long-term psychosocial functioning of youth who completed CBT for anxiety.

\section{Parent involvement in CBT and LTFU of Parent-involved CBT for Youth Anxiety}

Given etiologic evidence implicating parent influences on child anxiety disorders (see Hudson \& Rapee, 2005), parent involvement in CBT (CBT+P) in youth anxiety treatment has been proposed as a potentially fruitful avenue for improving short-term and long-term outcomes (Ginsburg, Silverman, \& Kurtines, 1995; Wood, McLeod, Sigman, Hwang, \& Chu, 2003). While parents have been explicitly included in some CBT programs (Barrett et al., 1996; Cobham, Dadds, \& Spence, 1998; Manassis, Avery, Butalia, \& Mendlowitz, 2004), the majority of CBT programs do not explicitly include parents for youth anxiety but are primarily child-focused, with a combination of common elements such as psychoeducation, relaxation training, gradual exposures, positive coping strategies, and social skills training (see Chorpita, Becker, \& Daleiden, 2007). Studies comparing ICBT and $\mathrm{CBT}+\mathrm{P}$ have yielded unclear and inconsistent results with respect to short-term efficacy (see Barmish \& Kendall, 2005); some studies found that CBT+P led to superior short-term diagnostic outcomes relative to ICBT (e.g., Barrett et al., 1996; 
Creswell \& Cartwright-Hatton, 2007; Mendlowitz, Manassis, Bradley, Scapillato, Miezitis, and Shaw, 1999; Wood, Piacentini, Southam-Gerow, Chu, \& Sigman, 2006; Wood, McLeod, Piacentini, \& Sigman, 2009), but other studies failed to find differences in short-term diagnostic outcomes between ICBT and CBT+P (e.g., Cobham et al., 1998; Kendall, Hudson, Gosch, \& Flannery-Schroeder, 2008; Silverman, Kurtines, Jaccard, \& Pina, 2009).

Also unclear is whether $\mathrm{CBT}+\mathrm{P}$ leads to superior long-term outcomes relative to ICBT. As noted, out of the 30 plus published studies demonstrating the short-term efficacy for CBT for anxiety disorders, 12 published studies have examined long-term outcomes of CBT for youth anxiety. Of these, only four examined parent involvement in youth CBT as part of a randomized controlled trial (Barrett et al., 2001; Manassis et al., 2004; Cobham, et al., 2010; Walczak, Esbjorn, Breinho;st, \& Reinholdt-Dunne, 2016) and one examined parent involvement in youth CBT using an "ex post facto" design and included participants who had received CBT for anxiety from an anxiety disorders specialty clinic with no random assignment (Adler Nevo et al., 2014).

In a study of 79 youth ages 7-14 (43\% female), Barrett, Dadds, and Rapee (1996) examined ICBT vs. CBTP+P for the treatment of anxiety disorders. At the post treatment evaluation, $69.8 \%$ of youth did not meet diagnostic criteria for any anxiety disorder, with a significant difference between treatment conditions. Youth in the ICBT condition reported lower diagnostic recovery rates than those in the $\mathrm{CBT}+\mathrm{P}$ condition, $57 \%$ versus $84 \%$, respectively. At the follow-up evaluation which included 52 youth ages 13-21 from the original sample of 79, Barrett et al. (2001) reported a diagnostic recovery rate of $85.7 \%$ over a 5 to 7 year follow-up period, with no significant difference between the 
ICBT and $\mathrm{CBT}+\mathrm{P}$ conditions at follow-up. Ratings on youth completed measures also showed maintenance of treatment gains on ratings of anxiety and depressive symptoms at the follow up period.

In a study of 63 youth ages 7 to 12 (57\% female), Mendlowitz, et al., (1999) examined CBT for youth anxiety disorders delivered in three formats: parent only-GCBT, child only-GCBT, or child and parent concurrent-GCBT. At the post treatment evaluation, a diagnostic interview was not conducted. Treatment effects were reported on symptom reduction on anxiety and depressive symptom rating scales, with no differences found between treatment condition on symptom ratings, but a significant difference in parent involved groups where parents rated their children as more improved than parents of children in the other two conditions. At a follow-up evaluation that included 43 youth ages 15-19 from the original sample of 63, Manassis et al., (2004) reported that 70\% did not require further treatment based on parent and child ratings of youth anxiety symptoms over a 6 to 7 year follow up period. Manassis et al. did not complete a diagnostic interview and thus were unable to report diagnostic recovery rates at the follow-up evaluation. There were no significant differences between the ICBT and CBT+P conditions at the follow-up evaluation.

In a study of 67 youth ages 7-14 (49\% female), Cobham, et al. (1998) examined youth GCBT or GCBT+P for the treatment of anxiety disorders. At the post treatment evaluation, $57 \%$ of youth whose parent met criteria for any anxiety disorder did not meet diagnostic criteria for an anxiety disorder themselves, while $81 \%$ of youth whose parent did not meet criteria for any anxiety disorder did not meet diagnostic criteria for an anxiety disorder themselves. There was no significant difference between treatment 
conditions at post. At a follow-up evaluation which included 60 youth ages 10-17 from the original sample of 67, Cobham et al. (2010) reported a diagnostic recovery rate of $80 \%$ over a three year follow-up period, with no significant difference between youth whose parents met criteria for an anxiety disorder versus those whose parents did not. There was a significant difference found between treatment conditions at follow-up: youth who completed GBT+P showed $92 \%$ anxiety diagnosis recovery and youth who received ICBT showed $75 \%$ anxiety diagnosis recovery.

In a study of 54 youth ages 7-12 (48\% female), Esbjorn, Reinholdt-Dunne, Nielsen, Smith, and Breinholst (2015) examined ICBT versus CBT $+\mathrm{P}$ for the treatment of anxiety disorders in youth. At the post treatment evaluation, $50 \%$ of youth did not meet diagnostic criteria for their primary anxiety disorder and $35 \%$ of youth did not meet criteria for any anxiety disorder. There was no significant difference between treatment conditions at post treatment. At a follow-up evaluation which included 40 youth ages 1117 from the original sample of 54, Walczak, et al., (2016) reported an overall diagnostic recovery rate of $74 \%$ over a three year follow-up period, with no significant difference between treatment groups in primary diagnostic status at the three year follow-up.

In a study of 120 youth ages 8-12 (54\% female) where half received CBT for anxiety disorders delivered in either individual or group format for youth with concurrent parents session and half received no intervention or treatment as usual (but not CBT), Adler Nevo et al. (2014) compared CBT intervention and treatment as usual eight years post treatment. At a follow-up evaluation, Adler Nevo, et al. (2014) reported an overall diagnostic recovery rate of $50 \%$ for youth in the treatment condition and $48.1 \%$ for youth in the treatment as usual (TAU) condition over an 8 year follow-up period, with no 
significant differences between conditions. This study differs from the studies reviewed above in that it included an assessed only group in its long-term follow-up assessment. This has been a limitation of other studies in that results presented have all included treatment completers and minimal dropped participants, which has not allowed to completely rule out effects of maturation and study outcomes. However, there are some serious limitations when comparing to the other studies reviewed above in that it did not use random assignment for treatment conditions, had a poor retention rate, and inconsistent measurement of anxiety symptom severity across participants given the study design. Additionally, participants at follow-up were lumped together from both group and individual CBT format. To the best of my knowledge, post treatment information was not available to compare to other studies above.

As reviewed in the preceding paragraphs, evidence for differential efficacy of $\mathrm{CBT}+\mathrm{P}$ and ICBT over long-term follow-ups is mixed. One possible reason for the mixed findings is that past long term follow-up studies have not specifically targeted parenting behaviors relevant to the development and maintenance of youth anxiety, such as parental reinforcement behaviors and parental relationship behaviors. Only one long term follow-up study included contingency management and transfer of control strategies in the parent-involved condition (Walcza et al., 2016), and this same study reported superior effects in the parent condition at the three year follow-up (Walcza et al., 2016). Further studies are needed to evaluate whether involving parents and targeting specific parenting behaviors in CBT for youth anxiety leads to superior long-term outcomes relative to youth ICBT. 
There is reason to believe targeting specific parenting behaviors may lead to improvements in long-term outcomes among youth with anxiety disorders. Parenting behaviors of low warmth and high control significantly predict higher levels of anxiety and depression in both short-term (Johnson \& Greenberg, 2013) and long-term (Ginsburg, Grover, \& Ialongo, 2004; Baker \& Hoerger, 2012). By extension, it is possible that specifically targeting parental behaviors of warmth and control may lead to long-term changes in parenting behaviors of warmth and control, which in turn may lead to superior long-term youth anxiety reduction outcomes. Consistent with this possibility, a recently published review (Manassis et al., 2014) concluded that active parental involvement in youth CBTs that targeted specific parenting practices such as parental use of reinforcement produced superior child outcomes at one-year follow-up compared to youth CBTs that did not target specific parenting strategies. The review did not evaluate follow ups beyond a one year period.

\section{Psychosocial Outcomes in LTFU of CBT for Youth Anxiety}

The presence of youth anxiety and its disorders is associated with impairment in social and academic functioning (for a review see Kingery, Erdley, Marshall, Whitaker, \& Reuter, 2010). With regards to social functioning, youth who suffer from anxiety are typically more reticent to interact with same-age peers, are less liked than their nonanxious peers, and have poorer social skills (e.g., eye contact, starting/maintaining a conversation). In a study examining peer perceptions of youth with anxiety disorders, Verduin and Kendall (2008) found that youth were able to pick up on their peer's anxiety symptoms, specifically social anxiety symptoms. Verduin and Kendall showed 100 youths ages 9 to 13 years videotapes of target peers giving a 2-minute speech and then 
measured the youths' perceptions of the target peer's anxiety symptoms, attitude/liking of the target peers, and probability of socializing with the target peers. Target peers who were rated as showing higher levels of anxiety symptoms also received lower ratings of liking and probability of socializing. Other studies have found similar results indicating that youth with high anxiety, and more specifically high social anxiety, have low rates of peer acceptance, high rates of peer rejection and high levels of negative peer outcomes (Inderbitzen, Walters, \& Bukowski, 1997; La Greca \& Lopez, 1998; Vernberg, Abwender, Ewell, \& Beery, 1992), including peer victimization (Erath, Flanagan, \& Bierman, 2007). There is some evidence that the relationship between youth anxiety and peer social outcomes may be bidirectional: anxiety leads to poor peer functioning and peer interactions, and impairments with peers leads to increases in anxiety over time (see Kingery et al., 2010).

With regards to academic functioning, studies have found significant associations between anxiety disorders and poor academic performance (e.g., Langley, Bergman, McCracken, \& Piacentini, 2004), including school drop out and tertiary education completion (Kessler, Foster, Saunders, \& Stang, 1995; Monroe Borzi, \& Burrell, 1992; Van Ameringen et al., 2003). High levels of anxiety, especially anxious cognitions and worrying, may lead to disrupted attention and concentration on schoolwork, resulting in poor academic performance (e.g., Ma, 1999; Nail et al., 2015). Further, high levels of social or performance anxiety may lead to insufficient class participation, avoidance of class presentations and working in groups, and failure to ask for clarification from teachers when material is not understood, also resulting in poor academic performance. 
The findings reviewed in the preceding two paragraphs demonstrate the presence of impairments in social functioning and academic functioning among youth with anxiety disorders. There also is evidence that CBT for youth anxiety can lead to improvements in social and academic functioning, at least in the short-term (i.e., by the end of treatment). For example, in a study of 40 youth with anxiety disorders who completed a CBT protocol, Wood (2006) found that both academic and social functioning improved from pre treatment to post treatment. Further, improvements in anxiety symptoms during treatment significantly predicted improvements in youth's academic performance and youths' social functioning by the end of treatment, suggesting that successfully reducing youth anxiety symptoms may be a promising route to enhance social and academic functioning.

To my knowledge, no studies have reported on the long-term social functioning of youth following CBT for anxiety. Only one follow-up study has reported on academic functioning in youth following CBT for anxiety (Saavedra et al., 2010), thus very little is known about how youth fare in academic performance following treatment for anxiety in the long-term. In short-term, studies have found that youth who have received CBT for anxiety also demonstrate improvements in academic functioning. For example, in a study of 94 youth with elevated symptoms of anxiety who completed a CBT protocol for test anxiety, Weems et al., (2009) found that academic functioning significantly improved from pre treatment to post treatment as measured by improvements in grade point average. Data from Walkup et al. (2008) discussed above, showed that youth with anxiety disorders who participate in CBT treatment for anxiety disorders displayed significant pre treatment to post treatment improvement in academic functioning, with 
greater improvement reported for youth who responded to treatment at post treatment (Nail et al., 2015).

Among 67 youth who completed either ICBT or GCBT and were reassessed in early adulthood 8 to 13 years post treatment, Saavedra et al. (2010) found that $17 \%$ of participants experienced delays in tertiary education, $50 \%$ of participants reported some college education, and $25 \%$ of participants reported completion of either an Associate or Bachelor's degree. The majority of the sample in Saavedra et al. was 18 years or older at the time of the follow-up assessment. No studies to my knowledge have reported on long-term academic functioning in youth who are in elementary or secondary school. Additionally, no studies to my knowledge have reported on long-term social functioning following CBT for anxiety disorders.

In the current dissertation project, I will examine anxiety outcomes and social and academic functioning outcomes at a long-term follow-up evaluation in youth who completed CBTs for anxiety disorders. Further, I will evaluate whether anxiety outcomes following CBT for anxiety mediate long-term social and academic functioning.

Additionally, I will evaluate the alternative mediation path in which social and academic functioning may mediate anxiety outcomes at follow-up. Preliminary evidence from Wood (2006) suggests anxiety reductions might mediate social and academic functioning outcomes, but no study to my knowledge has evaluated the reverse path in which social and academic functioning improvements mediate anxiety reductions. Understanding if social and academic functioning following CBT for anxiety mediates long-term outcomes in adolescence could inform the utility of these variables as predictors of treatment relapse or retention of diagnosis and related impairments. In this dissertation project, I 
define social functioning as the presence of positive social relationships with others, including same-age peers and practice/participation in extracurricular group activities. I define academic functioning as sustained performance in academic achievement, including maintaining passing grades and no grade retention.

Summary, Research Objectives and Hypotheses

The proposed dissertation project is expected to answer questions related to the long-term diagnostic outcomes and psychosocial functioning outcomes of youth who receive CBT for anxiety disorders. Given the state of the literature, the most important purpose was to examine whether CBT that specifically target parenting behaviors associated with youth anxiety $(\mathrm{CBT}+\mathrm{P})$ produces significantly lower levels of psychopathology (AIM 1) and higher levels of psychosocial functioning (AIM 2) as compared to ICBT at a follow-up evaluation ranging from one to seven years post treatment. Specifically, in AIM 1, I examined anxiety disorder diagnostic recovery rate for primary targeted anxiety disorder, anxiety disorder diagnostic recovery rate for any comorbid anxiety disorders present at pre treatment, diagnostic recovery rate for any comorbid mood or substance use disorders, anxiety symptom levels based on self- and parent-ratings on symptom questionnaires, and depressive symptom levels based on youth self-rating on symptom questionnaire. In AIM 2, I examined youth academic and social functioning using parent-ratings on the CBCL questionnaire. As an additional step in understanding the role of psychosocial outcomes in long-term outcomes, I examined directional associations between psychosocial and anxiety outcomes. That is, I examined whether (a) improvements in youth anxiety mediate improvements in youth psychosocial functioning, and (b) improvements in youth psychosocial functioning mediate 
improvements in youth anxiety (AIM 3). In addition to the proposed study aims, I conducted exploratory analyses to preliminarily examine whether there were statistically significant differences between two $\mathrm{CBT}+\mathrm{P}$ conditions on youth psychopathology outcomes and psychosocial outcomes at the follow-up evaluation: relationship skills training (RLST) or reinforcement skills training (RFST) (ancillary analyses).

Based on findings in other long-term follow-up studies on CBTs for youth anxiety, I expected that youth who showed positive treatment gains at post treatment would maintain these gains at the long-term follow-up period one to seven years following treatment. Maintained gains were assessed based on diagnostic status (e.g., no longer meeting criteria for primary targeted anxiety disorder and other anxiety disorders based on clinical interview) and ratings on self- and parent-report anxiety measures. It was expected that youth who received $\mathrm{CBT}+\mathrm{P}$ would show superior long-term outcomes at the follow up evaluation (i.e., lower levels of psychopathology and higher levels of psychosocial functioning) as compared to youth who received ICBT (Aims 1 and 2). It was further expected that improvements in youth anxiety would mediate improvements in youth psychosocial functioning (Aim 3). The reverse path from psychosocial functioning to youth anxiety was also examined although the path from academic functioning to anxiety has not been previously examined. There is no compelling theoretical argument as to why this path might be significant either in short-term or long-term. As such, I hypothesized improvement in anxiety would predict subsequent improvement in academics, but not the reverse path from improvement in academics to improvements in anxiety. These hypotheses were based on the rationale that (a) specifically targeting parenting behaviors that have been associated with child anxiety (i.e., parental 
reinforcement behaviors and parental relationship behaviors) would lead to sustained changes in parental behaviors which in turn would augment and sustain the anxiety reduction effects of CBT for youth with anxiety disorders (Aim 1) and (b) sustained reductions in youth anxiety and improvements in parent-child relationship quality would lead to higher levels of psychosocial functioning (Aim 2). 


\section{CHAPTER III}

\section{METHODS}

\section{Proposed Study}

The aims of this dissertation project were addressed in a subset of the total 264 youth who previously received CBT for anxiety as part of a randomized controlled clinical trial (RCT) conducted at the Child Anxiety and Phobia Program (CAPP) at Florida International University between 2009 and 2014. Data were collected from 173 individuals (66\% of original treatment sample) at a follow-up evaluation one to seven years post treatment using a multisource assessment approach.

Long-term psychopathology outcomes were assessed on the basis of diagnostic status rates and youth self-ratings and parent-ratings on anxiety and depressive symptom measures. Long-term psychosocial outcomes were assessed using parent report of youth functioning in academic and social contexts (see Measures section).

Participants. Participants were 173 youth (70 females, 102 males) and their mothers out of a possible 264 total participants who participated and completed the full treatment program in the aforementioned clinical trial of CBT for youth anxiety disorders (R01 MH079943). Given that data were only available on 173 of the 264 total participants, prior to outcome analysis, demographic variables and all post treatment scores were compared between the 91 youth who completed the post treatment assessment only and 173 youth who completed both the post and follow-up assessments. No significant differences were found between these groups.

Youth participants received either ICBT or CBT+P for anxiety disorders at the CAPP clinic. At the time of their first participation in treatment, all youth were between 
the ages of 5 and 15 years old $(M=9.33$ years, $S D=2.27)$. At the time of the long-term follow-up evaluation, these participants were between the ages of 7 and 17 years old ( $M$ $=11.27$ years, $S D=2.47$ ), with about one third of the sample between 12-17 years. The majority of treatment sessions were conducted in English (87.2\%), where 95.4\% of youth and $63.0 \%$ of mothers were primarily English-speakers. Regarding youth ethnicity, 82.0\% were Hispanic-Latino, $11.6 \%$ were European-American, 1.7\% were African American or Afro-Caribbean American, 1.2\% were Asian-American, and 3.5\% were Other ethnicity. Eighty-five percent of youth indicated they were born in the U.S. Mother ethnicity was reported as $80.2 \%$ Hispanic-Latino, $15.7 \%$ European-American, 1.7\% African American or Afro-Caribbean American, and 2.3\% Other ethnicity. Thirtyfour percent of mothers reported they were born in the U.S. The majority of foreign-born mothers were born in Latin America and the Caribbean. Of those born outside of the U.S., over half of the mothers indicated they had lived in the U.S. for 15 years or more. Inclusion criterion was a primary DSM-IV-TR diagnosis of an anxiety disorder determined by the Anxiety Disorders Interview Schedule for DSM-IV: Child and Parent Versions (ADIS-IV: C/P; silverman \& Albano, 1996). Exclusion criteria were the following: a diagnosis of primary externalizing disorder or pervasive developmental disorder (PDD), on the basis of a parent report of prior history or as obtained on the ADIS-IV:P; symptoms of psychosis such as hallucinations or delusions; imminent threat of self-injurious behaviors; and current involvement in other psychosocial or psychopharmacological treatment for anxiety. For youth who reported suicidal ideation or self-injurious behaviors, a thorough risk assessment and safety plan were completed and appropriate steps were taken to ensure safety. Youth who met criteria for primary 
ADHD or PDD were provided with appropriate referrals for further assessment and treatment as needed.

As mentioned above, all youth met a primary DSM-IV-TR diagnosis of an anxiety disorder determined by the ADIS child and parent interviews. Table 1 presents diagnostic information for youth in ICBT and CBT $+\mathrm{P}$ conditions. The most common targeted anxiety disorder was Separation Anxiety Disorder (SAD) (27\%, n = 44), followed by Social Phobia (SOP) $(22 \%, \mathrm{n}=36)$ and Generalized Anxiety Disorder (GAD) $(20 \%, \mathrm{n}=32)$. For the overall follow-up sample, primary targeted anxiety diagnostic recovery rates were $79 \%$ at post treatment and $69 \%$ at follow-up. Diagnostic recovery rates for any anxiety disorder were $65 \%$ at post treatment and $50 \%$ at follow-up. Beyond anxiety diagnostic status, $3 \%$ of participants met diagnostic criteria for a mood disorder (MDD or Dysthymia) at the pre treatment assessment, 1.2\% of participants met diagnostic criteria for a mood disorder at post treatment, and 3\% of participants met diagnostic criteria for a mood disorder at follow-up determined by ADIS child and parent interviews combined. Twenty-seven percent of the sample met diagnostic criteria for comorbid externalizing disorders (ADHD or ODD) at pre treatment, 11\% met diagnostic criteria for comorbid externalizing disorders at post treatment, and 10\% met diagnostic criteria for comorbid externalizing disorders at follow-up. Five percent of the sample was on anxiety medication at pre treatment, and this number dropped to $2 \%$ at both the post treatment and follow-up time points.

Treatment Conditions. The clinical trial from which participants in this dissertation were drawn examined different forms of CBT for youth anxiety. Despite some variations in format delivery (individual versus parent-involved), all conditions 
generally used the same therapeutic procedures common to CBT for anxiety (i.e., rapport building, psychoeducation, exposures, cognitive restructuring, and response prevention).

The trial examined youth ICBT and two forms of CBT with parent involvement. In each of the two parent involvement conditions, specific parenting strategies were targeted to enhance youths' treatment. In the first parent condition, Relationship Skills Training (RLST), the targets were increasing parental acceptance of the child (e.g., by demonstrating to the child that mother accepts them for who they are unconditionally) and improving the parent-child relationship by reducing parental over-involvement and psychological control (e.g., by granting the child more autonomy, as developmentally appropriate). In the second parent condition, Reinforcement Skills Training (RFST), the targets were increasing parental use of positive reinforcement and praise (e.g., by teaching the parent how to use reinforces such as tangible and non-tangible rewards upon successful completion of their child's exposure task) and decreasing negative reinforcement (e.g., by teaching parents to recognize how their child behaves when they are trying to avoid facing their fears and learning to how to support their child to approach, instead of avoid, feared situations). In the ICBT condition, youth received traditional CBT without a parenting component in an individual format (just youth and therapist).

For the purpose of the current dissertation, I combined the parent-involved treatments into one condition $(\mathrm{CBT}+\mathrm{P})$ and compared it to the youth condition where parents were not involved (ICBT). One reason parenting conditions were combined came from preliminary findings from the clinical trial of no differences in treatment outcome at immediate post across the two parent involvement conditions. Ancillary 
analyses were performed to gain insight into the possibility of differences between the parent-involved conditions at the follow up time point in this dissertation project.

\section{Measures}

In this section the following measures are described: A) measures used to assess long-term psychopathology outcomes; B) measures used to assess long-term psychosocial functioning outcomes; and C) demographic variables such as parent and youth ethnicity, youth gender, and treatment language. The measures chosen for the LTFU evaluation were based on measures administered at the pre treatment and post treatment assessment time points. While newer versions of some of the measures described below now exist, I decided to use the original measures from the pre treatment assessment time point to permit comparison on the same measure across time points.

\section{A. Measures Used to Assess Long-Term Psychopathology Outcomes}

\section{A1. Psychopathology Outcomes: Diagnostic Interview Schedule.}

\section{Anxiety Disorders Interview Schedule for DSM-IV: Child and Parent Versions}

(ADIS- IV: C/P; Silverman et al., 1996). The ADIS for DSM-IV: C/P was used to derive DSM-IV diagnoses. This interview schedule includes both a youth interview (ADIS-C) and a parent interview (ADIS-P). For the purposes of the current dissertation, both parent and youth were administered the ADIS-IV corresponding interviews. The ADIS has been shown to have excellent reliability for deriving diagnoses using youth, parent, and combined interviews (Silverman, Saavedra, \& Pina, 2001). Moreover, in addition to DSM-IV anxiety disorders, other related disorders such as affective (e.g., major depression, dysthymia) and externalizing disorders (e.g., ADHD and conduct disorder) were assessed using these interviews. 
The following diagnostic variables were assessed using the respective versions of the diagnostic interview. Anxiety disorder diagnostic status. Long-term follow-up effects for treatment of anxiety disorders were defined as the absence of any DSM-IV anxiety disorder. Rates of anxiety disorders were calculated using ADIS results for the a) primary targeted anxiety disorder, and b) any comorbid anxiety disorder present at intake pre-treatment (full remission). Anxiety sequelae. The development of any new psychiatric disorder (MDD, dysthymia, substance abuse disorder [SUD]) was defined as meeting DSM-IV criteria for a new psychiatric disorder that was not present either at intake pre-treatment or at the post-treatment evaluation.

\section{A2. Questionnaires Completed by Youth}

Revised Children's Manifest Anxiety Scale (RCMAS; Reynolds \& Richmond, 1978). The RCMAS was used to assess the long-term follow-up effects with respect to symptoms of anxiety. The RCMAS consists of 37 items that describe anxious symptoms relating to physiological, worry/over sensitivity, and concentration. Items are rated by youth by selecting either a Yes or No response for each statement, and scored 1 or 0 , respectively. There has been extensive work supporting the validity of the RCMAS (see manual, Reynolds \& Richmond, 1985). Additionally, the RCMAS has been used as a primary outcome measure in almost all previous childhood anxiety clinical trials and has been found to be a sensitive measure of change in these studies (e.g., Kendall, 1994; Kendall et al., 1997; Silverman et al., 1999a) as well as in long-term follow-up studies (Kendall et al., 1996; Barrett et al., 2001). Past studies have reported good internal consistency with estimates ranging from 0.78 to 0.85 in European American and African American samples (Reynolds \& Richmond, 2000) and .65 to .89 in a sample of Mexican 
American children living in the U.S. (Varela \& Biggs, 2006). For the current study, only the total score was used as a measure of global anxiety severity; the internal consistency for the total score subscale was comparable to past studies, $($ alpha $=.90)$.

Children's Depression Inventory (CDI; Kovacs, 1992). The CDI was used to assess the long-term follow-up effects with respect to symptoms of depression. The CDI is a 27-item measure rated on a 3-point scale used to assess the cognitive, affective, and behavioral symptoms of childhood depression within a 2-week period. The 27 items contain 3 statements scored in order of increasing severity from 0 to 2 . The CDI has satisfactory internal consistency (e.g., alpha $=.89)$ and retest reliability (e.g., $r=.98)$ and can discriminate among relevant groups. For the current study, internal consistency was comparable to past studies, $($ alpha $=.85)$

\section{A3. Questionnaires Completed by Parent}

Revised Children's Manifest Anxiety Scale, Parent Version (RCMAS-P; Reynolds et al., 1978). The RCMAS-P is a parallel measure to the RCMAS, adapted to obtain parent's perspective on child anxiety symptoms. In the RCMAS-P, the wording was changed from "I..." to "My child..." (e.g., Kendall, 1994; Silverman et al., 1999). Respondents rate each item as either Yes or No and scored 1 or 0 , respectively. Twentyeight items are summed to provide a Total Anxiety score. The RCMAS-P was also used to assess the long-term follow-up effects with respect to symptoms of anxiety from parent perspective. As with the youth RCMAS, only the total score was used in the current study as a measure of global anxiety severity; the internal consistency for the total score subscale was comparable to past studies, $($ alpha $=.90)$. 


\section{B. Measures Used to Assess Long-Term Psychosocial Outcomes}

\section{B1. Psychosocial outcomes via parent-report questionnaire}

Child Behavior Checklist (CBCL; Achenbach, 2001). The CBCL was used to assess psychosocial outcomes from parent perspective. The CBCL contains 118 items measuring specific symptom levels of youth problems. Each item is rated on a 3-point likert scale and is based on a 2-month period. The CBCL has been the prime parentcompleted rating scale used in past childhood anxiety trials and has been found to be sensitive to statistical and clinical change.

The academic performance and social functioning subscales were used to assess psychosocial functioning during the follow-up period. Strong psychometric properties and construct validity have been previously documented for the $\mathrm{CBCL}$, including these two subscales (Achenbach \& Rescorla, 2001). Both academic and social functioning subscales have been found to have good discriminant validity distinguishing between referred and non-referred youth (Achenbach et al., 2001). The social functioning subscale measures participation in extracurricular and group activities and the presence of positive social relationships. Support has been found for the social functioning subscale's concurrent validity via significant correlations with other anxiety measures, including the Social Phobia Anxiety Inventory for Child (SPAI-C) at $r=-.33$ (Beidel, Turner, \& Morris, 1995) and Child Anxiety Impact Scale at $r=-.40$ (Langley et al., 2014). Internal consistency has been reported to be $\alpha=.68$ and 1 -week test-retest reliability at $r=.93$. The academic functioning subscale measures academic performance, including problems in school, grade retention, or additional school services. Support has been found for the academic functioning subscale's concurrent validity via significant 
correlations with other reports of academic functioning, including the Child Anxiety Impact Scale at $r=-.25$ (Langley et al., 2014). Internal consistency has been reported to be $\alpha=.63$ and 1 -week test-retest reliability at $r=.90$. Past research has found these subscales to be sensitive to change following CBT intervention (Wood, 2006).

\section{Sociodemographics}

Sociodemographic Information. Parents were asked to complete a clinic information sheet to obtain background information from families, including sociodemographic information of the parent and youth such as primary language of parent, primary language of youth, years living in the U.S., maternal education, family income, and marital status. Specifically for this dissertation, demographic variables examined as potential covariates were parent and youth ethnicity, youth gender, youth age at pre treatment, treatment language, mother education, and marital status. Analyses revealed statistically significant differences on youth age at pre treatment, youth gender, and youth ethnicity. As such, youth age at pre treatment, youth gender, and youth ethnicity were included as covariates in all analyses run while also controlling for pre treatment scores and time since post treatment in months.

\section{Procedures}

All participants completed a follow-up evaluation one to seven years $(M=1.92$ years, $S D=1.11,9-83$ months) following CBT treatment for anxiety. The follow-up evaluation consisted of 1) a diagnostic interview, and 2) self- and parent-report questionnaires used to assess follow-up outcomes. Informed consent and assent were obtained prior to conducting interviews and administering any questionnaires. All interviews were conducted by doctoral level students trained in the administration of the 
respective interview schedules (ADIS and ADIS-IV: C/P). Weekly supervision was provided for all cases by the faculty advisors. Families were remunerated for their completion of study evaluations. 


\section{CHAPTER IV}

\section{RESULTS}

\section{Preliminary Data Analyses}

Data management protocols were used to ensure integrity of the data. Data were checked for out of range and missing values. Missing data were found to be minimal for most variables (and no more than 10 percent on any given variable), with the exception of the academic and social functioning variables that were excluded in some of the later follow-up assessments because of time constraints. Missing data for these two variables was almost a third (27\%). Where missing values occurred, missing data were accommodated by employing full information maximum likelihood (FIML) missing data methodology in MPLUS (Wothke, 2000). Missing data bias was assessed by computing a dummy variable reflecting the presence or absence of missing data for each variable in the model and then correlating the dummy variable with all other variables in the model, as well as an array of demographic variables (Jaccard Personal Communication). None of the correlations were statistically significant, indicating no evidence of bias.

Outlier analyses were undertaken prior to all major analyses. The analyses checked for both non-model based and model based outliers. For the former, multivariate outliers were identified by examining leverage indices for each individual and defining an

outlier as a leverage score four times greater than the mean leverage. An additional set of outlier analyses was pursued using model-based outlier analysis. Standardized dfbetas were examined for each individual and each predictor as well as the intercept. An outlier was defined as any case with an absolute standardized dfbeta larger than 1.0. No model based or non-model based outliers were detected. In addition, univariate indices of 
skewness and kurtosis were examined to determine if the absolute value of any of these indices was greater than 2.0. Examination of univariate indices of skewness and kurtosis revealed no absolute skewness value above 1.81 and no absolute kurtosis values above 2.71. The absolute kurtosis value for the CDI at the follow-up time point was above the recommended cut off. To account for the non-normality present in the data, structural equation modeling (SEM) analyses were pursued in the MPlus statistical software program by using an estimator (MLR) robust to violations of normality using the HuberWhite algorithm (Muthén \& Muthén, 2011).

Following the recommendations of Bollen and Long (1993), a variety of global fit indices were used for all SEM models, including indices of absolute fit, indices of relative fit, and indices of fit with a penalty function for lack of parsimony. These include the traditional overall chi-square test of model fit (which should be statistically non-significant), the Root Mean Square Error of Approximation (RMSEA; which should be less than 0.08 to declare satisfactory fit), the $\mathrm{p}$ value for the test of close fit (which should be statistically non-significant), the Comparative Fit Index (CFI; which should be greater than 0.95); the Tucker Lewis Index (TLI; which should be greater than 0.95); and the standardized root mean square residual (which should be less than 0.05).

The theoretical questions posed in this research are framed in individual path diagrams in Figures 1-7. Traditional structural equation modeling (SEM) strategies were used in MPlus statistical software. SEM uses full information estimation approaches where all of the path coefficients (and their standard errors) are estimated simultaneously in the context of the full system of linear equations implied by the model. An alternative approach is to use a limited information estimation strategy. The limited information 
estimation strategy approach uses the path diagram to identify the structural relationships of interest and to define the relevant linear equations. However, the overall model is broken up into pieces and estimates of the coefficients are derived within each piece separately using statistical methods that are appropriate for that piece. Full information estimation approaches can yield more efficient estimates and also yield more plentiful statistics about goodness of model fit. However, the full information estimation approach also has disadvantages. For example, model misspecification in one part of the model can yield biased estimates in another part of the model. By contrast, in limited information estimation, specification error is compartmentalized. Limited information estimation also allows one to tailor the analytic method to the nature of the variables involved in a given piece of the overall model (e.g., logistic regression, ordinal regression, OLS regression). Full information estimation strategies were pursued within an SEM framework for all analyses presented below (Jaccard Personal Communication).

The robustness of conclusions was compared with and without statistical corrections for multiple tests. A Holm adjusted modified Bonferroni method for controlling familywise error rates was used. Because all participants were previously enrolled in the clinical trial, and time since post treatment assessment varied between one to seven years post treatment, the time since post treatment in months was included as a covariate in all analyses. Analyses used families who were treatment completers and who participated in both the post and follow-up assessments $(n=173)$. Analyses were conducted to compare families who only completed the post assessment to families who completed both the post and follow-up assessments; results yielded no statistically significant differences in post scores on any of the outcome measures. Results presented 
below include the sample of 173 families who completed both the post and follow-up assessments.

Main Data Analyses

Psychopathology Outcomes

Aim 1 Diagnostic Status. The equivalent of binary logistic regression analyses were conducted using SEM in MPlus statistical software to evaluate diagnostic outcomes. Four separate binary logistic regression models were run to test whether there were significant differences between treatment conditions (ICBT or CBT+P) on anxiety, depression, or substance use at the follow-up evaluation. Specifically, regressions were run to examine diagnostic status of (1) primary targeted anxiety disorder, (2) any anxiety disorder, (3) any mood disorder, or (4) any substance abuse disorder.

First, a binary logistic regression analysis within an SEM framework was conducted to test whether the presence of the primary targeted anxiety disorder at followup significantly differed between youth in the ICBT condition $(n=64)$ and youth in the combined CBT $+\mathrm{P}$ conditions $(\mathrm{n}=109)$. There were no statistically significant differences on diagnostic recovery rates for primary targeted anxiety disorder between treatment conditions after controlling for immediate post diagnostic status and time since post treatment $(\mathrm{z}=1.00, p>05)$.

A second binary logistic regression analysis within an SEM framework was conducted to test whether the presence of any anxiety disorder at follow-up significantly differed between youth in the ICBT condition $(n=64)$ and youth in the combined CBT+P conditions $(\mathrm{n}=109)$. There were no statistically significant differences on diagnostic 
recovery rates for any anxiety disorder between treatment conditions after controlling for immediate post diagnostic status and time since post treatment $(\mathrm{z}=1.18, p>05)$.

To examine the association between treatment condition and anxiety sequela at follow-up, two additional binary logistic regression analyses within an SEM framework were conducted to test whether the for the presence of 1) MDD or 2) SUD at follow-up significantly differed between youth in the ICBT condition $(n=64)$ and youth in the combined CBT $+\mathrm{P}$ conditions $(\mathrm{n}=109)$. Outcome statistics could not be computed for MDD or SUD categories given the low number of participants who met criteria for either MDD or SUD at follow up. In total, only 6 participants met criteria for MDD at the follow-up evaluation (three were in the ICBT condition and three were in the combined CBT $+\mathrm{P}$ conditions). No participants met criteria for SUD at follow-up.

Aim 1 parent and youth ratings on questionnaires. To complete the second part of Aim 1, the SEM equivalent of linear regression models were conducted to test whether the levels of psychopathology at follow-up measured using youth self- and parent-ratings on symptom questionnaires significantly differed between youth in the ICBT condition $(n=64)$ and youth in the combined CBT+P conditions $(n=109)$. Specifically, three separate regressions were run to examine (1) parent ratings of youth anxiety on the RCMAS, (2) youth self-ratings of anxiety on the RCMAS, and (3) youth self-ratings of depression on the CDI.

Treatment condition significantly predicted scores on RCMAS parent ratings of youth anxiety symptoms at follow-up after controlling for immediate post RMCAS parent scores and time since post treatment, $(\mathrm{z}=3.41, \mathrm{p}<.001, \beta=2.44, S E=.72)$, with lower ratings for youth in the $\mathrm{CBT}+\mathrm{P}$ condition compared to the ICBT condition. After 
applying a Holmes modified Bonferonni correction, results remained statistically significant at $\mathrm{p}<.01$.

Treatment condition did not significantly predict scores on RCMAS youth selfratings of anxiety symptoms at follow-up after controlling for immediate post RCMAS scores and time since post treatment, $(\mathrm{z}=0.34, p>05)$.

Treatment condition did not significantly predict scores on CDI youth self-ratings of depressive symptoms at follow-up after controlling for immediate post CDI scores and time since post treatment $(\mathrm{z}=0.35, p>05)$.

\section{Youth Psychosocial Functioning Outcomes}

Aim 2. To examine psychosocial functioning at follow up (i.e., social and academic functioning), the SEM equivalent of two separate linear regression models were run to examine whether levels of functioning measured by parent ratings at follow-up significantly differed between youth in the ICBT condition $(n=64)$ and youth in the combined CBT $+\mathrm{P}$ conditions $(\mathrm{n}=109)$. Specifically, separate models were run to examine parent ratings of youth social functioning and youth academic functioning on the CBCL.

Parent ratings on youth social functioning. Treatment condition significantly predicted scores on parent-rated youth social functioning at follow-up after controlling for immediate post social functioning scores and time since post treatment, $(\mathrm{z}=-2.64, \mathrm{p}<$ $.05(\beta=-3.37, S E=1.28)$. Social functioning scores in the combined CBT $+\mathrm{P}$ conditions $(M=45.66, S D=8.85)$ were significantly higher than scores in the ICBT condition $(M=$ 41.81, $S D=9.32$ ), indicating superior social functioning for participants in the CBT $+\mathrm{P}$ parent conditions compared to participants in the youth only CBT condition. After 
applying a Holmes modified Bonferonni correction, results remained significant at $\mathrm{p}$ $<.01$.

Parent ratings on youth academic functioning. Treatment condition did not significantly predict scores on parent ratings of youth academic functioning at follow-up after controlling for immediate post academic functioning scores and time since post treatment, $(\mathrm{z}=0.27, p>05)$.

Directionality of Effects on Youth Psychosocial Functioning and Youth Anxiety

Aim 3. The data were further analyzed using SEM to examine the directionality of associations between youth anxiety and psychosocial outcomes at the post treatment and follow-up evaluations. That is, I examined whether (a) improvements in youth anxiety at post treatment mediated improvements in youth psychosocial functioning at follow-up, or (b) improvements in youth psychosocial functioning at post treatment mediated improvements in youth anxiety at follow-up.

A two-valued dummy variable (scored 1 or 0 ) for the two treatment conditions (ICBT versus $\mathrm{CBT}+\mathrm{P}$, respectively) was defined and was assumed to impact youth anxiety and psychosocial outcomes at the post treatment and at the follow-up time points. Paths were included from each of these variables to all endogenous variables. Separate analyses were conducted on youth self-ratings of anxiety and parent rated youth functioning, and for parent ratings of the youth anxiety and parent rated youth functioning.

Academic Functioning

A model was run to test whether treatment condition accounted for changes in youth anxiety symptoms and youth academic functioning from post treatment to the 
follow-up evaluation. Directional effects were included in the model to examine the direction of change between youth anxiety symptoms and youth academic functioning. The key paths of interest in Figure 6 are paths $a$ through $l$. Paths $a, b, c$, and $d$ represent contemporaneous effects in that treatment condition is assumed to impact changes in youth academic functioning at post treatment (path $a$ ) and follow-up (path $c$ ), and also youth anxiety at post treatment (path $b$ ) and follow-up (path $d$ ). Paths $e$ and $f$ represent traditional autoregressive effects in which change in a given variable from post treatment is associated with change in the same variable at follow-up. Paths $g$ and $h$ reflect lagged effects and estimate the extent to which changes in youth academic functioning from post treatment are associated with changes in youth anxiety symptoms at follow-up (path $h$ ), as well as the extent to which changes in youth anxiety symptoms from post treatment are associated with changes in youth academic functioning at follow-up (path $g$ ). Such lagged effects make theoretical sense because it may take time for the changes in one variable to work their way through and produce changes in the other variable. Path $i$ indicates that changes in youth anxiety symptoms at post treatment are assumed to be associated with changes in youth academic functioning at the same time point and path $j$ indicates that changes in youth anxiety symptoms at follow-up are assumed to be associated with changes in youth academic functioning at the follow-up time point. Paths $k$ and $l$ represent the reverse paths, such that changes in youth academic functioning at post treatment are assumed to be associated with changes in youth anxiety symptoms at the same time point (path $k$ ), and changes in youth academic functioning at follow-up are assumed to be associated with changes in youth anxiety symptoms at the follow-up time 
point (path $l$ ). Paths $m, n, o$, and $p$ are controlling for pre treatment scores on the outcome variables.

The fit of the model in Figure 6 was evaluated with MPlus statistical software using a maximum likelihood algorithm. The model is statistically overidentified. Prior to analysis, data were evaluated for multivariate outliers. No outliers were detected.

A variety of fit indices of model fit were evaluated. The chi-square test of model fit was statistically non-significant, $\mathrm{x}^{2}(2)=0.41, \mathrm{p}>0.05$. The Root Mean Square Error of Approximation (RMSEA) was .00. The $\mathrm{p}$ value for the test of close fit was .81 . The Comparative Fit Index (CFI) was 1.00 and the Tucker-Lewis Index (TLI) was 1.08. The Standardized Root Mean Square Residual (Standardized RMR) was 0.006. All indices point to good model fit. Inspection of the residuals revealed no statistically significant points of ill-fit in the model. There were no theoretically meaningful modification indices above 5, again indicating good model fit.

Figure 8 presents relevant unstandardized path coefficients. For purposes of presentation, the correlations between exogenous variables are omitted. The residuals indicate the proportion of unexplained variance in the endogenous variables (i.e., they are error variances in standardized form). The variables in the model accounted for approximately $35 \%$ of the variance in youth self-rated RCMAS post scores and $53 \%$ of the variance in RCMAS follow-up scores. The variables in the model accounted for approximately $62 \%$ of the variance in youth academic functioning post scores and $58 \%$ of the variance in youth academic functioning follow-up scores. Path coefficients from treatment condition to post anxiety and youth academic functioning were statistically significant, as were path coefficients from post anxiety and youth academic functioning 
to follow-up anxiety and youth academic functioning. There were no statistically significant direct total effects from treatment condition to anxiety and academic functioning scores at the follow-up time point. There were also no statistically significant directional effects found between anxiety at post and academic functioning at follow-up, or academic functioning at post and anxiety at follow-up.

Table 8 presents the $95 \%$ confidence intervals for each of the unstandardized path coefficients in the model. The model suggests an impact of treatment condition on anxiety scores and youth academic functioning scores at post treatment. Paths $a$ and $b$ were statistically significant, suggesting that treatment condition was found to result in lower anxiety scores (2.39 units) and higher academic functioning scores ( 2.37 units) for youth in the combined CBT+P conditions compared with youth in the ICBT condition. Path $f$ was also statistically significant, where anxiety scores at post treatment were found to impact anxiety scores at the follow-up (.52 units). In regards to academic functioning scores, path $e$ was also statistically significant suggesting that academic functioning scores at post treatment impacted academic functioning scores at the follow-up (.28 units).

The same model was run based on parent report of youth anxiety. For ease of readability, all paths were kept the same from the youth model and the reader is directed to description above for detailed path explanation. The chi-square test of model fit was statistically non-significant, $x^{2}(2)=0.56, p>0.05$. The Root Mean Square Error of Approximation (RMSEA) was .00. The p value for the test of close fit was .81. The Comparative Fit Index (CFI) was 1.00 and the Tucker-Lewis Index (TLI) was 1.07. The 
Standardized RMR was 0.006. All indices point to good model fit. Examination of the modification indices (MIs) revealed no theoretically meaningful MIs greater than 5 .

Figure 9 presents relevant unstandardized path coefficients. For purposes of presentation, the correlations between exogenous variables are omitted. The residuals indicate the proportion of unexplained variance in the endogenous variables (i.e., they are error variances in standardized form). The variables in the model accounted for approximately $32 \%$ of the variance in parent rated RCMAS post scores and $54 \%$ of the variance in RCMAS follow-up scores. The variables in the model accounted for approximately $63 \%$ of the variance in youth academic functioning post scores and $60 \%$ of the variance in youth academic functioning follow-up scores. Path coefficients from treatment condition to post academic functioning and follow-up anxiety were statistically significant, as were path coefficients from post anxiety and youth academic functioning to follow-up anxiety and youth academic functioning. Path coefficients from post anxiety to post academic functioning and follow-up anxiety to follow-up academic functioning were also statistically significant. There were no statistically significant directional effects found between anxiety at post and academic functioning at follow-up, or academic functioning at post and anxiety at follow-up.

Table 9 presents the $95 \%$ confidence intervals for each of the unstandardized path coefficients in the model. The model suggests an impact of treatment condition on anxiety scores at follow-up and youth academic functioning scores at post treatment. Paths $a$ was statistically significant, suggesting that treatment condition was found to result in higher academic functioning at post treatment (1.77 units) for youth in the combined $\mathrm{CBT}+\mathrm{P}$ conditions compared with youth in the ICBT condition. There was 
also a statistically significant direct total effect from treatment condition to anxiety scores at the follow-up time point (path $d$ ), where lower anxiety scores were found for youth in the combined CBT+P conditions (2.76 units) compared to youth in the ICBT condition. Path $f$ was also statistically significant, where anxiety scores at post treatment were found to impact anxiety scores at the follow-up (.58 units). In regards to academic functioning, path $e$ was also statistically significant suggesting that academic functioning at post treatment impacted academic functioning scores at the follow-up (.28 units). Paths $i$ and $j$ were also statistically significant, where post anxiety was found to impact academic functioning at post (-.27 units) and follow-up anxiety was also found to impact academic functioning at follow-up (-.35 units). The reverse paths, $k$ and $l$ were also statistically significant, where post academic functioning was found to impact youth anxiety at post (-.20 units) and follow-up academic functioning was also found to impact youth anxiety at follow-up (-.18 units).

\section{Social Functioning}

A second set of models was run to examine whether treatment condition accounted for change in youth anxiety symptoms and ratings of youth social functioning at post treatment and follow-up. Directional effects were included in the model to examine the direction of change between youth anxiety symptoms and youth social functioning. For ease of readability, the same paths used in the previous models were included in the models below. The paths of interest in Figure 7 are paths $a$ through $l$. Paths $a, b, c$, and $d$ represent contemporaneous effects in that treatment condition is assumed to impact changes in youth social functioning at post treatment (path $a$ ) and follow-up (path $c$ ) youth anxiety at post treatment (path $b$ ) and follow-up (path $d$ ). Paths 
$e$ and $f$ represent traditional autoregressive effects in which change in a given variable from post treatment is associated with change in the same variable at follow-up. Paths $g$ and $h$ reflect lagged effects and estimate the extent to which changes in youth social functioning from post treatment are associated with changes in youth anxiety symptoms at follow-up (path $h$ ), as well as the extent to which changes in youth anxiety symptoms from post treatment are associated with changes in youth social functioning at follow-up (path $g$ ). Such lagged effects make theoretical sense because it may take time for the changes in one variable to work their way through and produce changes in the other variable. Path $i$ indicates that changes in youth anxiety symptoms at post treatment are assumed to be associated with changes in youth social functioning at the same time point and path $j$ indicates that changes in youth anxiety symptoms at follow-up are assumed to be associated with changes in youth social functioning at the follow-up time point. Paths $k$ and $l$ represent the reverse paths, that changes in youth social functioning at post treatment are assumed to be associated with changes in youth anxiety symptoms at the same time point (path $k$ ), and changes in youth social functioning at follow-up are assumed to associated with changes in youth anxiety symptoms at the follow-up time point (path $l$ ). Paths $m, n, o$, and $p$ are controlling for pre treatment scores on the outcome variables.

The model is statistically overidentified. A variety of indices of model fit were evaluated. The chi-square test of model fit was statistically non-significant, $x^{2}(2)=5.38$, $p>0.05$. The Root Mean Square Error of Approximation (RMSEA) was .10. The $p$ value for the test of close fit was .15. The Comparative Fit Index (CFI) was 0.99 and the Tucker-Lewis Index (TLI) was .79. The Standardized RMR was 0.030. Most fit indices 
point to good model fit with the exception of the TLI and RMSEA. Examination of the modification indices (MIs) revealed no theoretically meaningful MIs greater than 5 .

Figure 10 presents relevant standardized and unstandardized (in parentheses) path coefficients in the model. The variables in the model accounted for approximately $33 \%$ of the variance in youth self-rated RCMAS post scores and $54 \%$ of the variance in RCMAS follow-up scores. The variables in the model accounted for approximately $35 \%$ of the variance in social functioning post scores and $52 \%$ of the variance in social functioning follow-up scores. The path coefficient from treatment condition to post anxiety was statistically significant, as well as the path coefficients from treatment condition to social functioning at follow-up. Path coefficients from post anxiety to follow-up anxiety and from post social functioning to follow-up social functioning were also significant. There was also a significant path from post anxiety to post social functioning. There were no statistically significant directional effects found between anxiety at post and social functioning at follow-up, or between social functioning at post and anxiety at follow-up.

Table 10 presents the $95 \%$ confidence intervals for each of the unstandardized path coefficients in the model. The model suggests an impact of treatment condition on anxiety scores at post treatment. Path $b$ was statistically significant, where combined $\mathrm{CBT}+\mathrm{P}$ conditions were found to result in lower anxiety scores at post (2.59 units) compared with the ICBT condition. There was also a direct total effect from treatment condition to social functioning at the follow-up time point (path $c$ ), where higher social functioning was found for youth in the combined $\mathrm{CBT}+\mathrm{P}$ conditions (3.41 units) compared with youth in the ICBT condition. Paths $e$ and $f$ were also found to be 
statistically significant, where anxiety scores at post treatment were found to impact scores at the follow-up (.52 units), and social functioning at post also impacted social functioning at follow-up (.42 units). Path $i$ was also statistically significant, where post anxiety was found to impact social functioning at post (-.22 units). The reverse path (path $k$ ) from post social functioning to post anxiety was also statistically significant $(-.10$ units).

As with the academic functioning models above, for parent report of youth anxiety and social functioning, the same model was tested based on parent report of youth anxiety and social functioning predictors from post treatment to follow-up. For ease of readability, all paths were kept the same from the youth model and the reader is directed to description above for detailed path explanation. The baseline model for parent report showed poor model fit on the chi-square estimate $(6.94, \mathrm{df}=2, \mathrm{p}<0.05)$, RMSEA (.12), and TLI (.69). The CFI was within acceptable range (.98), as was the Standardized RMR (.03) and p close ( $\mathrm{p}>.05)$. Examination of the modification indices (MIs) revealed four MIs greater than 5. Thus, the path estimates should be interpreted with caution given the marginal to poor model fit on some indices. Figure 11 presents relevant unstandardized path coefficients in the model

The variables in the model accounted for approximately $31 \%$ of the variance in RCMAS post scores and 55\% of the variance in RCMAS follow-up scores. The variables in the model accounted for approximately $37 \%$ of the variance in social functioning post scores and $52 \%$ of the variance in social functioning follow-up scores. The path coefficient from treatment condition to follow-up anxiety was statistically significant, as was the path coefficient from treatment condition to social functioning at 
follow-up. Path coefficients from post anxiety to follow-up anxiety and from post social functioning to follow-up social functioning were also significant. There was also a significant path from post anxiety to post social functioning. There were no statistically significant directional effects found between anxiety at post and social functioning at follow-up, or social functioning at post and anxiety at follow-up.

Table 11 presents the $95 \%$ confidence intervals for each of the unstandardized path coefficients in the model. The model suggests an impact of treatment condition on anxiety and social functioning scores at the follow-up. There was a statistically significant direct total effect from treatment condition to social functioning at the followup time point (path $c$ ), where higher social functioning was found for youth in the combined CBT $+\mathrm{P}$ conditions (3.27 units) compared with youth in the ICBT condition. There also was a statistically significant direct effect from treatment condition to anxiety at the follow-up (path $d$ ), where lower anxiety scores at post (2.68 units) were found for youth in the combined CBT+P conditions compared with youth in the ICBT condition. Paths $e$ and $f$ were also statistically significant, where anxiety scores at post treatment were found to impact scores at the follow-up (.59 units), and social functioning at post also impacted social functioning at follow-up (.41 units). Path $i$ was also statistically significant, where post anxiety was found to impact social functioning at post (-.32 units). The reverse path (path $k$ ) from post social functioning to post anxiety was also statistically significant (-.12 units).

Ancillary Data Analyses

Exploratory analyses were conducted to determine whether there were any differences between the two parenting conditions (RLST, RFST) on psychopathology and 
psychosocial functioning outcomes at the follow-up evaluation. Specifically, the SEM equivalent of binary logistic regression analyses were run to examine diagnostic status of primary targeted anxiety disorder, any anxiety disorder, any mood disorder, or any substance abuse disorder to examine differences by parent treatment condition.

Diagnostic Status. The equivalent of a binary logistic regression analysis was conducted to examine whether the odds of meeting diagnostic criteria for the primary targeted anxiety disorder at follow-up significantly differed between youth in the RLST condition $(n=38)$ and youth in the RFST condition $(n=71)$. Parent condition did not significantly predict whether youth met diagnostic criteria for their primary targeted anxiety disorder at follow-up in either condition, $(\mathrm{z}=1.02, \mathrm{p}>.05)$.

The equivalent of a binary logistic regression analysis was conducted to examine whether the odds of meeting diagnostic criteria for any anxiety disorder at follow-up significantly differed between youth in the RLST condition ( $\mathrm{n}=38)$ and youth in the RFST condition ( $n=71$ ). Parent condition did not significantly predict whether youth met diagnostic criteria for their targeted anxiety disorder at follow-up in either condition, ( $\mathrm{z}=$ $.65, \mathrm{p}>.05)$.

To examine the association between parent condition and anxiety sequela at follow-up, the equivalent of two binary logistic regression analyses were conducted to examine whether the odds of meeting diagnostic criteria for 1) MDD or 2) SUD at follow up significantly differed between youth in the RLST condition $(\mathrm{n}=38)$ and youth in the RFST condition ( $\mathrm{n}=71$ ). Outcome statistics could not be computed for MDD or SUD categories given that only 6 participants met criteria for MDD at the follow-up evaluation 
(only three participants were in the $\mathrm{CBT}+\mathrm{P}$ condition) and no participants met criteria for SUD at follow-up.

Parent and youth ratings on questionnaires. Rates of psychopathology at followup were also examined using self- and parent-ratings to assess anxiety and depressive symptoms. The equivalent of a linear regression model was conducted to examine whether levels of functioning measured by parent ratings at follow-up significantly differed between youth in the RLST condition $(n=38)$ and youth in the RFST condition $(\mathrm{n}=71)$. Specifically, the equivalent of a regression was conducted to examine parent ratings of youth anxiety on the RCMAS, youth self-ratings of anxiety on the RCMAS, and youth self-ratings of depressive symptoms on the CDI.

Anxiety ratings. Parent treatment condition did not significantly predict scores on parent ratings of youth anxiety symptoms at follow-up after controlling for immediate post RCMAS parent scores and time since post treatment, $(\mathrm{z}=.76, \mathrm{p}>.05)$.

Parent treatment condition also did not significantly predict scores on RCMAS youth self-ratings of anxiety symptoms at follow-up after controlling for immediate post RCMAS scores and time since post treatment, $(\mathrm{z}=.68, \mathrm{p}>.05)$.

Youth self-ratings on depression. Parent treatment condition did not significantly predict scores on CDI youth self-ratings of depressive symptoms at follow-up after controlling for immediate post CDI scores and time since post treatment, $(\mathrm{z}=-.29, \mathrm{p}>$ $.05)$.

Youth Psychosocial Functioning Outcomes. Psychosocial functioning was also examined at follow-up to determine whether levels of academic and social functioning measured by parent ratings at follow-up significantly differed between youth in the RLST 
condition $(n=38)$ and youth in the RFST condition $(n=71)$. The SEM equivalent of two separate linear regression models were regressions analyses were conducted to examine parent ratings of youth social functioning and youth academic functioning as reported on the CBCL.

Academic Functioning. Parent treatment condition did not significantly predict scores on parent ratings of youth academic functioning at follow-up after controlling for immediate post academic functioning scores and time since post treatment, $(z=-1.69, p>$ $.05)$.

Social Functioning. Parent treatment condition did not significantly predict scores on parent ratings of youth social functioning at follow-up after controlling for immediate post academic functioning scores and time since post treatment, $(\mathrm{z}=0.48, p>$ $05)$. 


\section{CHAPTER V}

\section{DISCUSSION}

The present study sought to answer questions related to the long-term psychopathology and psychosocial functioning outcomes of youth who received CBT for anxiety disorders. Given the state of the literature, the most important purpose was to examine whether CBT+P produced significantly lower levels of psychopathology (AIM 1) and higher levels of psychosocial functioning (AIM 2) as compared to youth ICBT at a follow-up evaluation ranging from one to seven years post treatment. As an additional step in understanding the role of psychosocial outcomes in long-term anxiety outcomes, I examined directional effects of psychosocial and anxiety outcomes. That is, I examined whether (a) improvements in youth anxiety mediated improvements in youth psychosocial functioning, or (b) improvements in youth psychosocial functioning mediated improvements in youth anxiety (AIM 3). In addition to the proposed study aims, I also conducted exploratory analyses to examine whether there were any differences between the two parent involved conditions (RLST or RFST) on long-term psychopathology outcomes and psychosocial outcomes (ancillary analyses).

\section{Primary Anxiety Outcomes}

Results from the present dissertation indicate that youth who demonstrated positive treatment gains at post treatment maintained these gains in their targeted primary anxiety concerns one to seven years following treatment. Maintenance of gains was evident on diagnostic status and youth- and parent-ratings of youth anxiety symptoms. The diagnostic recovery rate for targeted primary anxiety disorder was approximately $70 \%$ at follow-up evaluation, comparable to rates reported in previous long-term follow- 
up studies (Beidel et al., 2005; Beidel et al., 2006; Ginsburg et al., 2014). The diagnostic recovery rate for any anxiety disorder was $50 \%$ at follow-up, a rate that is comparable to rates reported in some long-term follow-up studies (Ginsburg et al., 2014), but lower than rates reported in other studies (Barrett et al., 2001; Cobham et al., 2010; Saavedra et al., 2010).

Treatment condition, CBT+P or ICBT, did not significantly distinguish whether youth met diagnostic criteria for their targeted primary anxiety disorder or any anxiety disorder at the follow-up evaluation. Additionally, among youth participants who received $\mathrm{CBT}+\mathrm{P}$, the specific parent condition (RLST or RFST) did not significantly predict whether youth met diagnostic criteria for their targeted primary anxiety disorder or any anxiety disorder at follow-up. The absence of differences between treatment conditions in the present study is consistent with findings of some past follow-up studies that involved parents in treatment of youth anxiety disorders (Barrett et al., 2001), but inconsistent with other studies (Cobham et al., 2010; Walczak et al., 2016) that found superior diagnostic outcome at follow-up in parent-involved conditions compared with youth ICBT. While the Cobham study focused on parental anxiety as a parent factor to target during treatment, the Walczak study is most similar to the current study as it targeted specific parenting behaviors and included contingency management and transfer of control strategies in the active parent condition (similar to RFST condition). The present findings indicate that targeting parent behaviors in CBT led to no enhanced outcomes with respect to anxiety disorder diagnoses.

When examining youth anxiety severity assessed by anxiety rating scales, youth and parent completed measures indicated maintenance of treatment gains at follow-up 
across conditions, consistent with other long-term follow-up studies reviewed above. Further, treatment condition significantly predicted parent ratings of youth anxiety symptoms at follow-up. Parent ratings of youth anxiety symptoms were significantly higher for youth in the ICBT condition compared with youth in the combined CBT+P conditions, indicating lower youth anxiety severity for participants in the parent-involved treatments. Treatment condition did not significantly predict youth self-ratings of anxiety symptoms at follow-up. Additionally, when comparing parent treatment conditions separately, there were no significant differences on parent- or youth self-ratings of anxiety symptoms at follow-up.

\section{Other Diagnostic Outcomes}

The rates of other, non-anxiety psychopathologies at the follow-up evaluation were very low. Only six participants (3\%) met diagnostic criteria for MDD at follow-up and zero participants met criteria for SUD at follow-up. The rate of mood disorder found in the present study was substantially lower than those reported in some long-term follow-up studies (Benjamin et al., 2013; Kendall et al., 2004), but comparable to rates found in other studies (Beidel et al., 2006; Saavedra et al., 2010). One possible explanation for the observed difference is the difference in measurement periods across studies. In the Kendall et al., (2004), diagnostic outcomes were reported for occurrence throughout the follow-up period (i.e., period prevalence), whereas in the Beidel and Saaverda studies, diagnostic outcomes were assessed and reported for current rates at the follow-up period only (i.e., point prevalence), as was done in the current study. It would be expected that point prevalence rates would be lower than period prevalence rates, especially for disorders like MDD that follow an episodic course. The rate of substance 
use disorders in the present study was also lower than rates reported in previous longterm follow-up studies (Benjamin et al., 2013; Kendall et al., 2004; Saavedra et al., 2010), with the exception of Beidel and colleagues (2006) who also reported that none of the participants at follow-up met criteria for a substance use disorder.

Despite the low number of youth who met criteria for MDD, maintenance of gains was evident on youth self-ratings of depressive symptoms. Treatment condition did not significantly predict youth self-ratings of depressive symptoms at follow-up, when comparing ICBT versus CBT+P or RFTS versus RLST. It should be noted, however, that the very low rate of depression may have limited statistical power to detect a difference between treatment conditions.

\section{Psychosocial Outcomes}

Beyond diagnostic status and symptoms of psychopathology, I examined youth academic and social functioning at the follow-up. To my knowledge, this is the first long-term follow-up study to examine social functioning and to compare different parenting conditions as they relate to youth long-term functioning. Treatment condition significantly predicted scores on parent rated youth social functioning at follow-up. Social functioning scores in the combined $\mathrm{CBT}+\mathrm{P}$ condition were significantly higher than social functioning scores in the ICBT condition, indicating superior social functioning for participants in the parent-involved treatment conditions. In contrast, treatment condition did not significantly predict scores on parent ratings of youth academic functioning at follow-up time. When examining the parent treatment conditions separately (RFST or RLST), parent treatment condition did not significantly 
predict scores on parent ratings of youth social functioning or academic functioning at the follow up evaluation.

\section{Directionality of Associations}

I also examined the directionality of associations between psychosocial outcomes and anxiety symptom severity in this dissertation project. That is, I evaluated whether improvements in youth anxiety would lead to improvements in psychosocial outcomes, and the reverse path from psychosocial outcomes to youth anxiety. While improvements in anxiety symptoms have been shown to also lead to improved academics and social functioning in the short-term (e.g., Wood, 2006), to my knowledge, this is the first longterm follow-up study to evaluate bidirectional affects. Although I found significant crosssectional associations between youth anxiety symptoms and psychosocial functioning at immediate post and again at follow-up, I found no evidence for directional effects from post to follow-up period in this dissertation project. The absence of lagged, directional effects suggests that a third variable may explain fluctuations in both anxiety symptoms and psychosocial functioning. Future research will be necessary to consider and examine potential third variables that may explain such fluctuations.

\section{Clinical Implications.}

\section{Parental involvement in CBT}

The study's findings provide further support for the efficacy and maintenance of ICBT and CBT+P for youth anxiety up to seven years post treatment. Further, this study went beyond past studies by examining $\mathrm{CBT}+\mathrm{P}$ conditions that targeted specific parenting practices associated with youth anxiety. Past studies that examined parentinvolved CBTs for youth anxiety included parents as "consultants", typically providing 
information for assessment and check-ins during weekly tasks, with little to no involvement in treatment content or sessions. Of the four prior long-term follow-up studies that involved parents in their child's treatment, there was variability in the format of parental involvement, ranging from collaborators in anxiety psychoeducation and ways to support exposure tasks (e.g., Mendlowitz et al., 1999) to co-clients, targeting parents' own anxiety (Cobham et al., 1998), or some combination of both (Barrett et al., 1996; Esbjorn et al., 2015). In the parent conditions of the present study, parents were involved as collaborators, where parents participated in each treatment session along with youth to help support newly learned skills and apply to exposure tasks outside of sessions. The collaborator role allowed for parents to continue to support youth even after treatment ended through the "transfer of control" model (see Ginsburg et al., 1995; Silverman \& Kurtines, 1996) where parents are able to learn alongside youth different skills to reduce anxious distress and behavioral avoidance through practice exposure tasks to promote behavioral change. Given the mixed findings related to parental involvement in the treatment of youth anxiety, results from the current study lend partial support for inclusion of parents in the treatment of youth anxiety disorders as collaborators to treatment. Specifically in this study, parental involvement had an enhancing effect on parent ratings of youth anxiety symptoms and social functioning at the follow-up evaluation.

In terms of youth functioning, parent report of youth anxiety symptoms showed lower symptom ratings and higher social functioning for youth in the parent conditions compared to participants in the youth only condition at follow-up. These findings are consistent with conclusions from a review that active parental involvement in youth 
CBTs that targeted specific parenting practices such as parental use of reinforcement produced superior child outcomes at one-year follow-up compared to youth CBTs that did not target specific parenting strategies (Manassis et al., 2014). While this dissertation project did not test whether parent involvement in treatment led to changes in parenting practices, results did show differential findings for parent- versus youth self-ratings on youth anxiety symptom ratings for participants in the parent conditions, with lower scores on parent ratings of youth anxiety in the combined $\mathrm{CBT}+\mathrm{P}$ condition relative to the ICBT condition. Additionally, social functioning scores in the combined CBT+P condition were also higher than scores in the ICBT condition per parent report, indicating higher levels of social functioning for participants in the parent conditions relative to the ICBT condition.

One interpretation of this pattern of findings is that $\mathrm{CBT}+\mathrm{P}$ led to better long-term youth anxiety outcomes and social functioning outcomes compared with ICBT. An alternative, but not mutually exclusive interpretation, is that actively involving parents and targeting parenting behaviors in treatment led parents to believe that youth anxiety outcomes are better (whether they really are or not). The latter interpretation could be consistent with the phenomenon of cognitive dissonance, or also could reflect the possibility that parents become more attuned to their children's levels of anxiety after participating actively in treatment. Another possibility is that parents who believe their children have experienced reductions in anxiety may be more likely to behave differently toward their children (e.g., behave in less controlling ways), which in turn may lead to actual reductions in youth anxiety symptoms over the long term. I did not test that possibility in my dissertation study. 


\section{Limitations and Future Directions.}

Results should be interpreted in light of the study's strengths and limitations. One strength of the current study is the relatively large and well-characterized sample. Participants in this study differed from past long-term follow-up studies in that the sample was majority Hispanic-Latino whereas almost all other long-term follow-up studies used samples that were almost entirely European-American, European-Australian, or European-Canadian. As such, results from this current study extend the literature on the long-term functioning of youth who receive treatment for anxiety to a primarily Hispanic-Latino sample. While this study included families from different Hispanic nationalities and countries of origin, of the largest representation was families of primarily Cuban and Colombian decent (17\% and 10\%, respectively). Future studies should examine whether differences exist between Hispanic-Latino groups and the generalizability of the present findings to other samples. Other relevant cultural variables to examine might include levels of acculturation and its role in the treatment of youth anxiety disorders, with particular attention to parenting beliefs and parenting practices in ethnic minority families. For example, among Hispanic-Latino families, respeto is a central part of parent rearing practices, with a heavy emphasis among Hispanic-Latinos on obedience to parents, polite manners, listening to elders, and respectful public behavior (Calzada, Fernandez, \& Cortes, 2010). The centrality of respeto to parenting practices among Hispanic-Latino families is congruent with high levels of parental control, and high levels of parental control are significantly associated with anxiety related problems among children, including Hispanic-Latino children (Rapee, 1997; Varela \& Hensley-Maloney, 2009; Wood, McLeod, Sigman, Hwang, \& Chu, 2003). 
A limitation of this study is that parenting practices targeted within each parent condition (e.g., psychological control, warmth) were not analyzed as potential mediators. It is recommended that future studies examine parenting practices as mediators of longterm treatment outcomes as understanding "how" treatment works would have important implications for refining and streamlining treatments.

Another limitation of this dissertation is measurement of social and academic functioning, which may not have fully captured important aspects of functioning as it relates to anxiety disorders. For example, for the purposes of this dissertation, social functioning was defined as the ability to form and maintain positive interpersonal functioning in relationships with others, including same-age peers based on parent's perspective. Other components of social functioning include specific social skills necessary for successful social interactions. Further, only parent ratings were available on youth psychosocial functioning. It will be important for future studies to include multi-informant ratings of social functioning to better capture social functioning in multiple contexts and multiple perspectives (e.g., self, peer, teacher) to better understand and support functioning beyond treatment. Similarly, academic functioning was assessed using parent report of grade retention, school accommodations (e.g., ESE or pull-out services), or academic performance in core subjects (e.g., reading, math, science). Other ways of measuring academic functioning might include review of report cards, teacher report of school performance and any specific interference observed due to anxiety concerns (e.g., loss of concentration due to anxiety, test anxiety).

Additionally, the present study's findings were obtained from a sample of youth who received services within an anxiety specialty clinic. That is, all study clinicians 
received extensive training on youth anxiety disorders and treatment delivery by experts in the anxiety field. Future research is encouraged to examine long-term outcomes of CBTs for youth anxiety in non-specialty clinic settings, such as community based mental health centers.

\section{Conclusions}

In view of its strengths and limitations, results of this dissertation study indicate that youth who demonstrated positive treatment gains at post treatment continued to maintain these gains at the long-term follow-up period one to seven years following treatment. Treatment condition significantly predicted parent ratings of youth anxiety symptoms at follow-up, with superior outcomes for participants in the parent-involved CBT conditions compared to participants in the youth only CBT condition. Treatment condition also significantly predicted parenting ratings of youth social functioning at follow-up, with superior social functioning for participants in the parent-involved CBT conditions compared to participants in the youth only CBT condition. No other differences were found related to treatment condition and youth functioning at the longterm follow-up. Results also showed cross-sectional bidirectional associations between academic functioning and anxiety symptoms, at both post and follow-up time points, and cross-sectional bidirectional associations between social functioning and anxiety symptoms, at post treatment. However, there were no lagged directional effects from post to follow-up. 
Table One.

Demographic and Diagnostic Information by Treatment Condition

\begin{tabular}{|c|c|c|c|c|c|c|c|c|}
\hline \multirow[b]{2}{*}{ Variable } & \multicolumn{4}{|c|}{$\operatorname{ICBT}(n=64)$} & \multicolumn{4}{|c|}{ CBT-P $(n=109)$} \\
\hline & $n$ & $\%$ & $M$ & $S D$ & $n$ & $\%$ & $M$ & $S D$ \\
\hline $\begin{array}{l}\text { Age (years) } \\
\text { at PRE }\end{array}$ & & & 9.16 & 2.27 & & & 9.43 & 2.28 \\
\hline Gender (female) & 19 & 30 & & & 51 & 46 & & \\
\hline \multicolumn{9}{|l|}{ Target diagnosis at PRE } \\
\hline Separation anxiety & 16 & 26.2 & & & 28 & 27.7 & & \\
\hline Social phobia & 7 & 11.5 & & & 29 & 28.7 & & \\
\hline Specific phobia & 12 & 19.7 & & & 17 & 16.8 & & \\
\hline Generalized anxiety & 13 & 21.3 & & & 19 & 18.8 & & \\
\hline OCD & 3 & 4.9 & & & 0 & 0.0 & & \\
\hline Panic Disorder & 4 & 6.5 & & & 4 & 4.0 & & \\
\hline Selective Mutism & 6 & 9.8 & & & 4 & 4.0 & & \\
\hline \multicolumn{9}{|c|}{ Youth Ethnic background } \\
\hline Euro-American & 7 & 10.9 & & & 13 & 11.9 & & \\
\hline Hispanic/Latino & 53 & 82.8 & & & 88 & 80.7 & & \\
\hline African-American & 1 & 1.6 & & & 2 & 1.8 & & \\
\hline Asian-American & 0 & 0 & & & 2 & 1.8 & & \\
\hline Other/not reported & 3 & 4.7 & & & 4 & 3.8 & & \\
\hline \multicolumn{9}{|c|}{ Family reported annual income } \\
\hline$\$ 0-\$ 20,999$ & 13 & 20.3 & & & 19 & 17.4 & & \\
\hline$\$ 21,000-\$ 40,999$ & 8 & 12.5 & & & 21 & 19.3 & & \\
\hline$\$ 41,000-\$ 60,999$ & 10 & 15.6 & & & 15 & 13.8 & & \\
\hline$\$ 61,000-\$ 80,999$ & 8 & 12.5 & & & 17 & 15.6 & & \\
\hline$\$ 81,000-\$ 99,999$ & 5 & 7.8 & & & 13 & 11.9 & & \\
\hline$\$ 100,000-\$ 149,999$ & 12 & 18.8 & & & 14 & 12.8 & & \\
\hline$>\$ 150,000$ & 2 & 3.1 & & & 6 & 5.5 & & \\
\hline Not reported & 6 & 9.4 & & & 4 & 3.7 & & \\
\hline \multicolumn{9}{|l|}{ Marital Status } \\
\hline Married & 57 & 89.0 & & & 92 & 84.4 & & \\
\hline Divorced & 2 & 3.1 & & & 10 & 9.2 & & \\
\hline Single & 2 & 3.1 & & & 5 & 4.6 & & \\
\hline Separated & 0 & 0.0 & & & 1 & 0.9 & & \\
\hline Remarried & 0 & 0.0 & & & 0 & 0.0 & & \\
\hline \multicolumn{9}{|l|}{ Unmarried living } \\
\hline w/ partner & 1 & 1.6 & & & 1 & 0.9 & & \\
\hline Widowed & 1 & 1.6 & & & 0 & 0.0 & & \\
\hline Not reported & 1 & 1.6 & & & 0 & 0.0 & & \\
\hline
\end{tabular}

Note. Obsessive Compulsive Disorder $=$ OCD. 
Table One. (continued)

Demographic and Diagnostic Information by Treatment Condition

\begin{tabular}{|c|c|c|c|c|}
\hline \multirow[b]{2}{*}{ Variable } & \multicolumn{2}{|c|}{$\operatorname{ICBT}(n=64)$} & \multicolumn{2}{|c|}{$\mathrm{CBT}+\mathrm{P}(n=109)$} \\
\hline & $n$ & $\%$ & $n$ & $\%$ \\
\hline \multicolumn{5}{|l|}{ Mother's Education } \\
\hline Grade school & 1 & 1.6 & 2 & 1.8 \\
\hline Some high school & 0 & 0.0 & 1 & 0.9 \\
\hline High school & 4 & 6.3 & 7 & 6.4 \\
\hline GED & 3 & 4.7 & 3 & 2.8 \\
\hline Some college & 8 & 12.5 & 11 & 10.1 \\
\hline College & 6 & 9.4 & 17 & 15.6 \\
\hline Bachelor's & 16 & 25.0 & 30 & 27.5 \\
\hline Master's & 15 & 23.4 & 15 & 13.8 \\
\hline Ph.D. & 1 & 1.6 & 1 & 0.9 \\
\hline Technical Degree & 6 & 9.4 & 16 & 14.7 \\
\hline Advanced Degree & 1 & 1.6 & 4 & 3.7 \\
\hline Other/Not Reported & 3 & 4.7 & 2 & 1.8 \\
\hline \multicolumn{5}{|l|}{ Father's Education } \\
\hline Grade school & 0 & 0.0 & 2 & 1.8 \\
\hline Some high school & 1 & 1.6 & 3 & 2.8 \\
\hline High school & 8 & 12.5 & 11 & 10.1 \\
\hline GED & 1 & 1.6 & 5 & 4.6 \\
\hline Some college & 14 & 21.9 & 13 & 11.9 \\
\hline College & 6 & 9.4 & 14 & 12.8 \\
\hline Bachelor's & 14 & 21.9 & 24 & 22.0 \\
\hline Master's & 7 & 10.9 & 13 & 11.9 \\
\hline Ph.D. & 1 & 1.6 & 1 & 0.9 \\
\hline Technical Degree & 6 & 9.4 & 10 & 9.2 \\
\hline Advanced Degree & 0 & 0.0 & 5 & 4.6 \\
\hline Other/Not Reported & 5 & 7.8 & 6 & 7.4 \\
\hline
\end{tabular}

Note . Mother's Education $=$ Highest education mother attained. Father's Education $=$ Highest education father attained. 
Table Two.

Mean (Standard Deviations) for Youth and Parent Completed Outcome Measures for Full Treatment Completer Sample

\begin{tabular}{lcccc}
\hline & \multicolumn{2}{c}{ Treatment Complete $(n=264)$} & \multicolumn{2}{c}{ FU Sample $(n=173)$} \\
\cline { 2 - 5 } & Pre & Post treatment & Pre & Post \\
& $M$ & $S D$ & $M$ & treatment \\
\hline Primary Outcome Youth & & & & \\
RCMAS-C & $11.80(6.41)$ & $7.15(6.10)$ & $11.82(6.33)$ & $7.31(6.41)$ \\
CDI & $9.22(6.73)$ & $6.01(6.57)$ & $9.19(6.71)$ & $6.60(7.14)$ \\
Primary Outcome Parent & & & & \\
RCMAS-P & $13.23(5.72)$ & $8.37(5.66)$ & $12.87(5.79)$ & $7.92(5.45)$ \\
ACA Comp & $45.81(8.88)$ & $47.45(8.02)$ & $45.94(8.67)$ & $46.70(8.24)$ \\
SOC Comp & $40.75(9.47)$ & $43.76(9.16)$ & $40.87(9.37)$ & $43.36(9.22)$ \\
\hline
\end{tabular}

Note. RCMAS/C = Revised Children's Manifest Anxiety/Child Version; RCMAS/P = Revised Children's Manifest Anxiety/Parent Version; CDI = Children's Depression Inventory; ACA Comp = CBCL Academic Functioning Subscale; SOC Comp = CBCL Social Functioning Subscale. 
Table Three.

Mean (Standard Deviations) for Youth and Parent Completed Outcome Measures

\begin{tabular}{|c|c|c|c|c|c|c|}
\hline & \multicolumn{3}{|c|}{ ICBT $(n=64)$} & \multicolumn{2}{|c|}{$\mathrm{CBT}+\mathrm{P}(n=109)$} & \multirow[b]{2}{*}{ Follow-Up } \\
\hline & $\begin{array}{c}\text { Pre } \\
\text { treatment } \\
M, S D\end{array}$ & $\begin{array}{c}\text { Post } \\
\text { treatment } \\
M, S D\end{array}$ & Follow-Up & $\begin{array}{c}\text { Pre } \\
\text { treatment } \\
M, S D\end{array}$ & $\begin{array}{c}\text { Post } \\
\text { treatment } \\
M, S D\end{array}$ & \\
\hline \multicolumn{7}{|l|}{ Youth Report } \\
\hline RCMAS-C & $11.69(6.43)$ & $8.88 \quad(6.83)$ & $6.26(5.77)$ & $12.12(6.29)$ & $6.36 \quad(5.85)$ & $4.51 \quad(5.13)$ \\
\hline $\mathrm{CDI}$ & $9.72 \quad(6.80)$ & $8.11 \quad(7.67)$ & $5.80 \quad(6.59)$ & $8.93 \quad(6.47)$ & $5.74 \quad(6.55)$ & $4.22 \quad(4.62)$ \\
\hline \multicolumn{7}{|l|}{ Parent Report } \\
\hline RCMAS-P & $13.03(6.12)$ & $8.68 \quad(5.82)$ & $9.24 \quad(6.62)$ & $12.82(6.12)$ & $7.59 \quad(5.17)$ & $5.54 \quad(4.25)$ \\
\hline ACA Comp & $43.22(8.71)$ & $44.13(8.89)$ & $46.21(8.14)$ & $46.30(8.87)$ & $48.02(7.60)$ & 47.95 (6.99) \\
\hline SOC Comp & $39.07(9.19)$ & $42.63(8.91)$ & $41.81(9.32)$ & $41.47(9.42)$ & $43.68(9.29)$ & $45.66(8.85)$ \\
\hline
\end{tabular}

Note. $\mathrm{RCMAS} / \mathrm{C}=$ Revised Children's Manifest Anxiety/Child Version;

RCMAS/P = Revised Children's Manifest Anxiety/Parent Version; CDI = Children's Depression Inventory; ACA Comp = CBCL Academic Functioning Subscale;

SOC Comp $=$ CBCL Social Functioning Subscale. 
Table Four.

Parameter Estimates and Confidence Intervals for Binary Logistic Regression Analyses for Categorical Outcomes by Treatment Condition

\begin{tabular}{lccccc}
\hline \multicolumn{5}{c}{ ICBT versus CBT+P } \\
& $\begin{array}{c}\text { Estimate } \\
\text { (SE) }\end{array}$ & Z-score & $95 \%$ CI & $\begin{array}{c}P \\
\text { value }\end{array}$ \\
\cline { 2 - 6 } & & & & & \\
Outcome & & & Lower & Higher & \\
\hline Tariable & 0.07 & 1.00 & -.04 & 0.18 & 0.32 \\
Any ANX DX & $\begin{array}{c}(0.07) \\
0.09\end{array}$ & 1.18 & -0.04 & 0.23 & 0.24 \\
Any MDD DX & $\begin{array}{c}(0.08) \\
\text { no }\end{array}$ & calculated & & & \\
Any SUD DX & estimates & as constant & & & \\
\hline
\end{tabular}

Note. $\mathrm{CI}=$ Confidence Interval; Target $\mathrm{DX}=$ Target Diagnosis; Any ANX DX = Any Anxiety Diagnosis; Any MDD DX = Any

Depression Diagnosis; Any SUD DX = Any Substance Abuse Diagnosis. 
Table Five.

Parameter Estimates and Confidence Intervals for Binary Logistic Regression Analyses for Categorical Outcomes by Parenting Condition

\begin{tabular}{|c|c|c|c|c|c|}
\hline \multirow{3}{*}{ Outcome } & \multicolumn{4}{|c|}{ RFST versus RLST } & \multirow{2}{*}{$\begin{array}{c}P \\
\text { value }\end{array}$} \\
\hline & \multirow{2}{*}{$\begin{array}{c}\text { Estimate } \\
\text { (SE) }\end{array}$} & \multirow[t]{2}{*}{ z-score } & \multicolumn{2}{|c|}{$95 \% \mathrm{CI}$} & \\
\hline & & & Lower & Higher & \\
\hline Target DX & $\begin{array}{c}0.08 \\
(0.08)\end{array}$ & 1.02 & -0.05 & 0.20 & 0.31 \\
\hline Any ANX DX & $\begin{array}{c}0.06 \\
(0.09)\end{array}$ & 0.65 & -0.09 & 0.21 & 0.52 \\
\hline Any MDD DX & no & calculated & & & \\
\hline Any SUD DX & estimates & as constant & & & \\
\hline
\end{tabular}

Note. $\mathrm{CL}=$ Confidence Interval; Target $\mathrm{DX}=$ Target Diagnosis; Any ANX DX = Any Anxiety Diagnosis; Any MDD DX = Any

Depression Diagnosis; Any SUD DX = Any Substance Abuse Diagnosis. 
Table Six.

Summary of Multiple Regression Analyses for Outcome Variables by Treatment Condition

\begin{tabular}{lccccc}
\hline \multicolumn{5}{c}{ ICBT versus CBT+P } \\
& $\begin{array}{l}\text { Estimate } \\
(\mathrm{SE})\end{array}$ & Z-score & $95 \%$ CI & $\begin{array}{c}P \\
\text { value }\end{array}$ \\
\cline { 2 - 6 } $\begin{array}{l}\text { Outcome } \\
\text { Variable }\end{array}$ & & & Lower & Higher & \\
\hline RCMAS-C & 0.24 & 0.34 & -0.91 & 1.31 & 0.73 \\
RCMAS-P & $\begin{array}{c}(0.70) \\
2.44\end{array}$ & 3.41 & 1.27 & 3.62 & $0.001^{* *}$ \\
CDI & $\begin{array}{c}(0.72) \\
0.30\end{array}$ & 0.35 & -1.12 & 1.72 & 0.73 \\
ACA Functioning & $\begin{array}{c}0.87) \\
0.30\end{array}$ & 0.27 & -1.53 & 2.12 & 0.79 \\
SOC Functioning & $\begin{array}{c}(1.11) \\
-3.37\end{array}$ & -2.64 & -5.47 & -1.27 & $0.008^{*}$ \\
\hline
\end{tabular}

Note. RCMAS/C = Revised Children's Manifest Anxiety/Child Version; RCMAS/P = Revised Children's Manifest Anxiety/Parent Version; CDI = Children's Depression Inventory; ACA Comp = CBCL Academic Functioning Subscale;

SOC Comp $=$ CBCL Social Functioning Subscale. 
Table Seven.

Summary of Multiple Regression Analyses for Outcome Variables by Parenting Condition

RFST versus RLST

\begin{tabular}{|c|c|c|c|c|c|}
\hline \multirow[b]{2}{*}{$\begin{array}{l}\text { Outcome } \\
\text { Variable }\end{array}$} & \multirow{2}{*}{$\begin{array}{c}\text { Estimate } \\
(\mathrm{SE})\end{array}$} & \multirow[t]{2}{*}{ Z-score } & \multicolumn{2}{|c|}{$95 \% \mathrm{CI}$} & \multirow{2}{*}{$\begin{array}{c}P \\
\text { value }\end{array}$} \\
\hline & & & Lower & Higher & \\
\hline RCMAS-C & $\begin{array}{c}0.56 \\
(0.82)\end{array}$ & 0.68 & -0.02 & 0.14 & 0.49 \\
\hline RCMAS-P & $\begin{array}{c}0.55 \\
(0.71)\end{array}$ & 0.76 & -0.63 & 1.72 & 0.45 \\
\hline CDI & $\begin{array}{l}-0.24 \\
(0.81)\end{array}$ & -0.29 & -1.58 & 1.10 & 0.77 \\
\hline ACA Functioning & $\begin{array}{l}-1.77 \\
(1.04)\end{array}$ & -1.69 & -3.48 & -0.05 & 0.09 \\
\hline SOC Functioning & $\begin{array}{c}0.67 \\
(1.40)\end{array}$ & 0.48 & -1.64 & 2.97 & 0.63 \\
\hline
\end{tabular}

Note. $\mathrm{RCMAS} / \mathrm{C}=$ Revised Children's Manifest Anxiety/Child Version; RCMAS/P = Revised Children's Manifest Anxiety/Parent Version; CDI = Children's Depression Inventory; ACA Comp = CBCL Academic Functioning Subscale;

SOC Comp $=$ CBCL Social Functioning Subscale. 


\section{Table Eight.}

Unstandardized Path Coefficients and 95\% Confidence Intervals for Youth Academic Functioning Model

\begin{tabular}{lcc}
\hline Path & Estimate & $\begin{array}{l}95 \% \\
\text { Confidence Interval }\end{array}$ \\
\hline Treatment Condition to Academic Functioning Post & -2.37 & -3.97 to -0.76 \\
Treatment Condition to Academic Functioning Follow-up & 0.46 & -1.41 to 2.33 \\
Treatment Condition to RCMAS Post & 2.40 & 1.02 to 3.78 \\
Treatment Condition to RCMAS Follow-up & 0.20 & -0.99 to 1.39 \\
Academic Functioning Pre to Academic Functioning Post & 0.70 & 0.62 to 0.77 \\
Academic Functioning Pre to Academic Functioning Follow-up & 0.39 & 0.22 to 0.56 \\
Academic Functioning Post to Academic Functioning Follow-up & 0.28 & 0.09 to 0.48 \\
Academic Functioning Post to RCMAS Post & 0.12 & -0.01 to 0.26 \\
Academic Functioning Post to RCMAS Follow-up & -0.08 & -0.16 to 0.01 \\
Academic Functioning Follow-up to RCMAS Follow-up & -0.05 & -0.18 to 0.08 \\
RCMAS Pre to RCMAS Post & 0.51 & 0.40 to 0.62 \\
RCMAS Pre to RCMAS Follow-up & 0.11 & 0.00 to 0.21 \\
RCMAS Post to RCMAS Follow-up & 0.52 & 0.40 to 0.64 \\
RCMAS Post to Academic Functioning Post & 0.13 & -0.02 to 0.27 \\
RCMAS Post to Academic Functioning Follow-up & -0.07 & -0.24 to 0.10 \\
RCMAS Follow-up to Academic Functioning Follow-up & -0.09 & -0.32 to 0.14 \\
\hline
\end{tabular}

Note. RCMAS = Revised Children's Manifest Anxiety/Child Version; Academic Functioning $=$ CBCL Academic Functioning Subscale. 
Table Nine.

Unstandardized Path Coefficients and 95\% Confidence Intervals for Parent Academic Functioning Model

\begin{tabular}{lcl}
\hline Path & Estimate & $\begin{array}{l}\text { 95\% } \\
\text { Confidence Interval }\end{array}$ \\
\hline Treatment Condition to Academic Functioning Post & -1.77 & -3.25 to -0.29 \\
Treatment Condition to Academic Functioning Follow-up & 1.21 & -0.68 to 3.09 \\
Treatment Condition to RCMAS Post & 0.66 & -0.60 to 1.92 \\
Treatment Condition to RCMAS Follow-up & 2.76 & 1.50 to 4.02 \\
Academic Functioning Pre to Academic Functioning Post & 0.64 & 0.56 to 0.71 \\
Academic Functioning Pre to Academic Functioning Follow-up & 0.41 & 0.25 to 0.58 \\
Academic Functioning Post to Academic Functioning Follow-up & 0.28 & 0.08 to 0.47 \\
Academic Functioning Post to RCMAS Post & -0.20 & -0.31 to -0.09 \\
Academic Functioning Post to RCMAS Follow-up & 0.01 & -0.09 to 0.10 \\
Academic Functioning Follow-up to RCMAS Follow-up & -0.18 & -0.30 to -0.06 \\
RCMAS Pre to RCMAS Post & 0.45 & 0.35 to 0.55 \\
RCMAS Pre to RCMAS Follow-up & 0.16 & 0.03 to 0.29 \\
RCMAS Post to RCMAS Follow-up & 0.58 & 0.44 to 0.72 \\
RCMAS Post to Academic Functioning Post & -0.27 & -0.41 to -0.14 \\
RCMAS Post to Academic Functioning Follow-up & 0.16 & -0.06 to 0.37 \\
RCMAS Follow-up to Academic Functioning Follow-up & -0.35 & -0.61 to -0.10 \\
\hline
\end{tabular}

Note. RCMAS = Revised Children's Manifest Anxiety/Parent Version; Academic Functioning $=$ CBCL Academic Functioning Subscale. 
Table Ten.

Unstandardized Path Coefficients and 95\% Confidence Intervals for Youth Social Functioning Model

\begin{tabular}{lll}
\hline Path & Estimate & $\begin{array}{l}95 \% \\
\text { Confidence Interval }\end{array}$ \\
\hline Treatment Condition to Social Functioning Post & 0.52 & -1.51 to 2.54 \\
Treatment Condition to Social Functioning Follow-up & $-3.41^{*}$ & -5.54 to -1.28 \\
Treatment Condition to RCMAS Post & $2.59^{*}$ & 1.24 to 3.94 \\
Treatment Condition to RCMAS Follow-up & 0.25 & -0.91 to 1.40 \\
Social Functioning Pre to Social Functioning Post & $0.56^{* *}$ & 0.42 to 0.70 \\
Social Functioning Pre to Social Functioning Follow-up & $0.29^{* *}$ & 0.16 to 0.42 \\
Social Functioning Post to Social Functioning Follow-up & $0.42^{* *}$ & 0.28 to 0.57 \\
Social Functioning Post to RCMAS Post & $-0.10^{*}$ & -0.19 to -0.02 \\
Social Functioning Post to RCMAS Follow-up & 0.07 & -0.01 to 0.15 \\
Social Functioning Follow-up to RCMAS Follow-up & -0.01 & -0.11 to 0.09 \\
RCMAS Pre to RCMAS Post & $0.53^{* *}$ & 0.42 to 0.63 \\
RCMAS Pre to RCMAS Follow-up & 0.09 & -0.01 to .20 \\
RCMAS Post to RCMAS Follow-up & $0.52^{* *}$ & 0.41 to 0.64 \\
RCMAS Post to Social Functioning Post & $-0.22^{*}$ & -0.39 to -0.04 \\
RCMAS Post to Social Functioning Follow-up & -0.03 & -0.26 to 0.19 \\
RCMAS Follow-up to Social Functioning Follow-up & -0.04 & -0.33 to $0-.25$ \\
\hline
\end{tabular}

Note. RCMAS = Revised Children's Manifest Anxiety/Child Version;

Social Functioning $=$ CBCL Social Functioning Subscale. 
Table Eleven.

Unstandardized Path Coefficients and 95\% Confidence Intervals for Parent Social Functioning Model

\begin{tabular}{lll}
\hline Path & Estimate & $\begin{array}{l}95 \% \\
\text { Confidence Interval }\end{array}$ \\
\hline Treatment Condition to Social Functioning Post & 0.34 & -1.68 to 2.37 \\
Treatment Condition to Social Functioning Follow-up & $-3.27^{*}$ & -5.36 to -1.18 \\
Treatment Condition to RCMAS Post & 0.86 & -0.44 to 2.15 \\
Treatment Condition to RCMAS Follow-up & $2.68^{* *}$ & 1.48 to 3.88 \\
Social Functioning Pre to Social Functioning Post & $0.52^{* *}$ & 0.39 to 2.37 \\
Social Functioning Pre to Social Functioning Follow-up & $0.30^{* *}$ & 0.16 to 0.44 \\
Social Functioning Post to Social Functioning Follow-up & $0.41^{* *}$ & 0.24 to 0.57 \\
Social Functioning Post to RCMAS Post & $-.012^{*}$ & -0.21 to -0.03 \\
Social Functioning Post to RCMAS Follow-up & 0.06 & -0.02 to 0.14 \\
Social Functioning Follow-up to RCMAS Follow-up & -0.07 & -0.15 to 0.01 \\
RCMAS Pre to RCMAS Post & $0.49^{* *}$ & 0.39 to 0.59 \\
RCMAS Pre to RCMAS Follow-up & $0.15^{*}$ & 0.03 to 0.28 \\
RCMAS Post to RCMAS Follow-up & $0.59^{* *}$ & 0.48 to 0.73 \\
RCMAS Post to Social Functioning Post & $-0.32^{*}$ & -0.57 to -0.08 \\
RCMAS Post to Social Functioning Follow-up & 0.21 & -0.09 to 0.51 \\
RCMAS Follow-up to Social Functioning Follow-up & -0.21 & -0.45 to 0.03 \\
\hline
\end{tabular}

Note. RCMAS = Revised Children's Manifest Anxiety/Parent Version; Social Functioning $=$ CBCL Social Functioning Subscale. 
Figure 1. Conceptual Model for Diagnostic Status

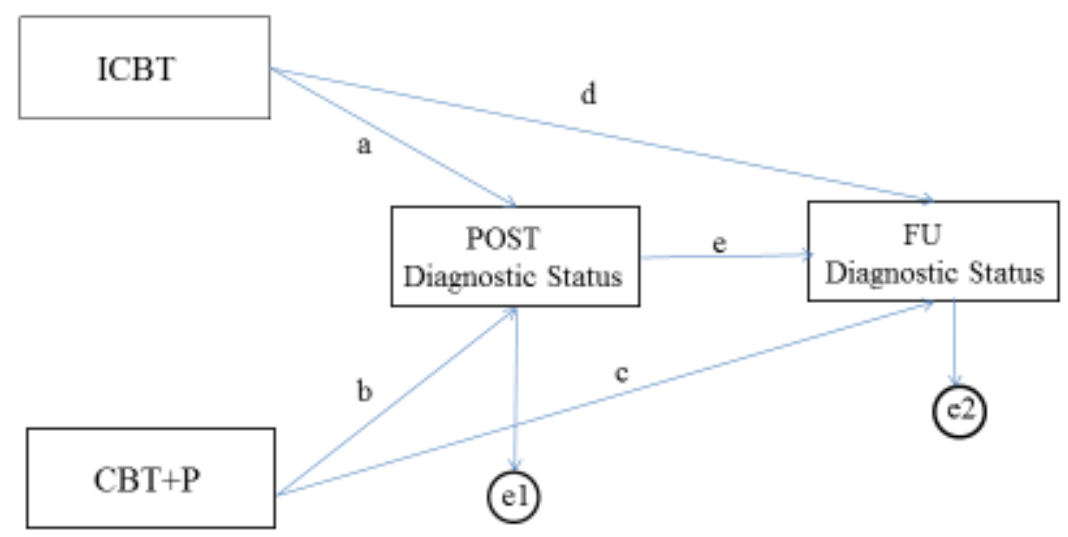

Note. $\mathrm{ICBT}=$ Individual $\mathrm{CBT}$ treatment approach; $\mathrm{CBT}+\mathrm{P}=\mathrm{CBT}$ with parental involvement. 
Figure 2. Conceptual Model for Anxiety Ratings

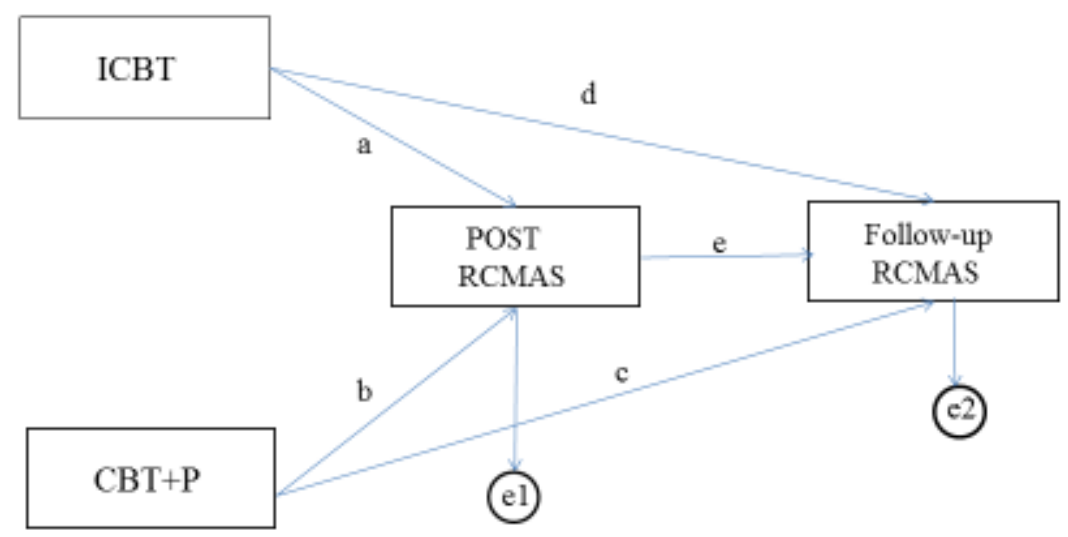

Note. RCMAS = Revised Children's Manifest Anxiety; ICBT= Individual CBT treatment approach; $\mathrm{CBT}+\mathrm{P}=\mathrm{CBT}$ with parental involvement. 
Figure 3. Conceptual Model for Depressive Ratings

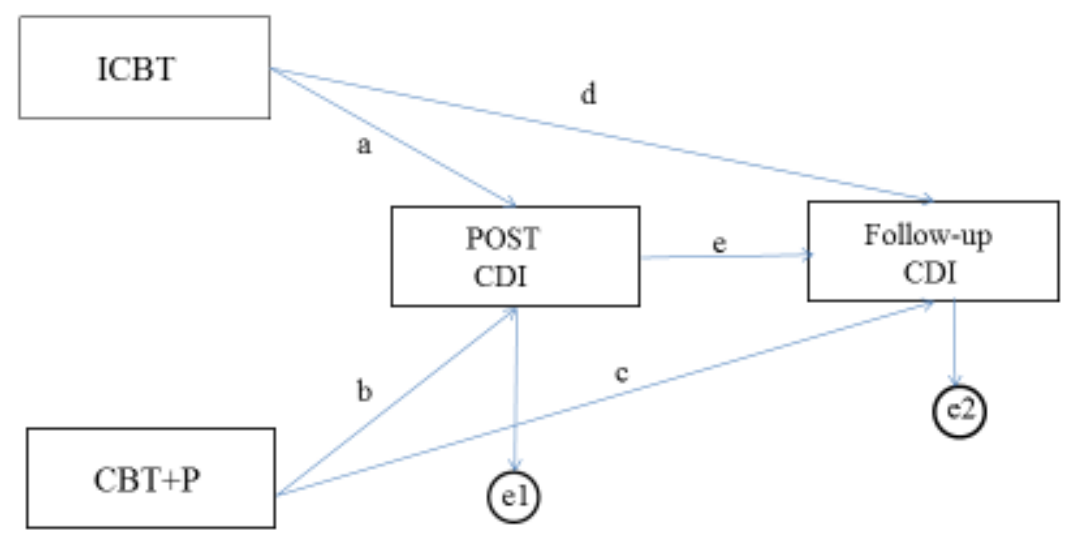

Note. CDI $=$ Children's Depression Inventory- Total Score; ICBT $=$ Individual CBT treatment approach; $\mathrm{CBT}+\mathrm{P}=\mathrm{CBT}$ with parental involvement. 
Figure 4. Conceptual Model for Academic Functioning

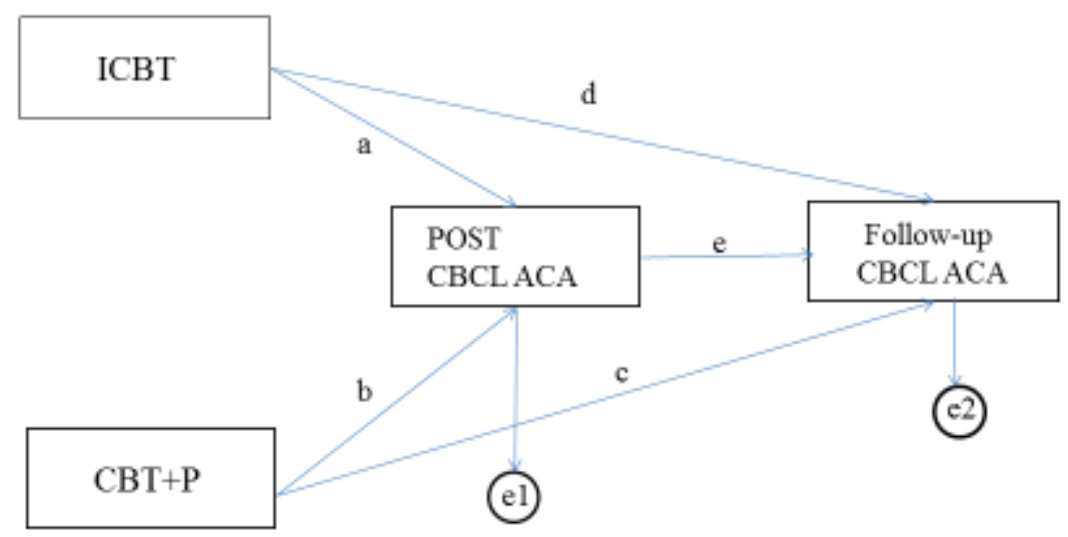

Note. CBCL ACA = CBCL Academic Functioning Subscale; $\mathrm{ICBT}=$ Individual CBT treatment approach; $\mathrm{CBT}+\mathrm{P}=\mathrm{CBT}$ with parental involvement. 
Figure 5. Conceptual Model for Social Functioning

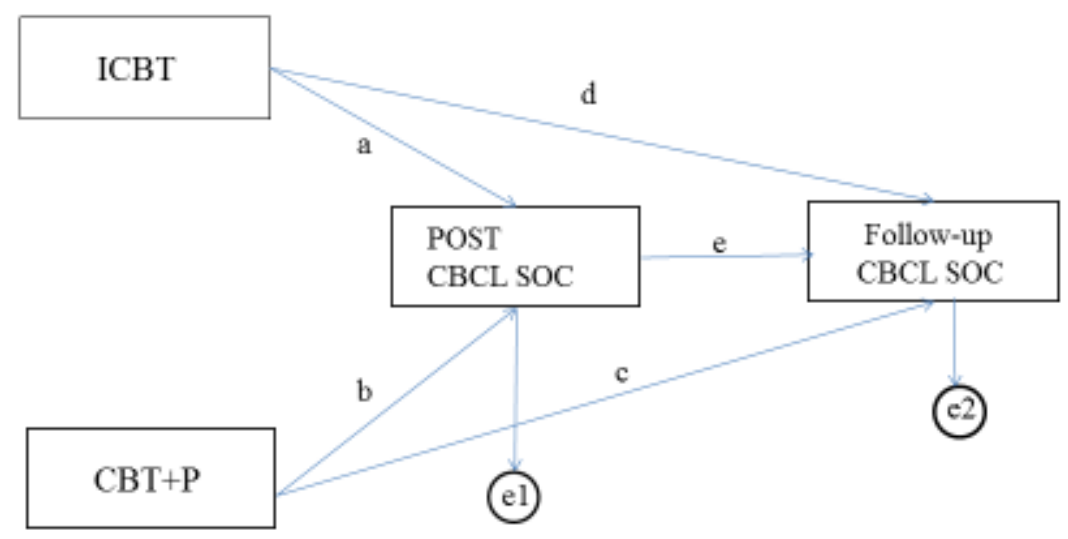

Note. CBCL SOC = CBCL Social Functioning Subscale; $\mathrm{ICBT}=$ Individual CBT treatment approach; $\mathrm{CBT}+\mathrm{P}=\mathrm{CBT}$ with parental involvement. 
Figure 6. Conceptual Model for Academic Functioning Lagged Effects

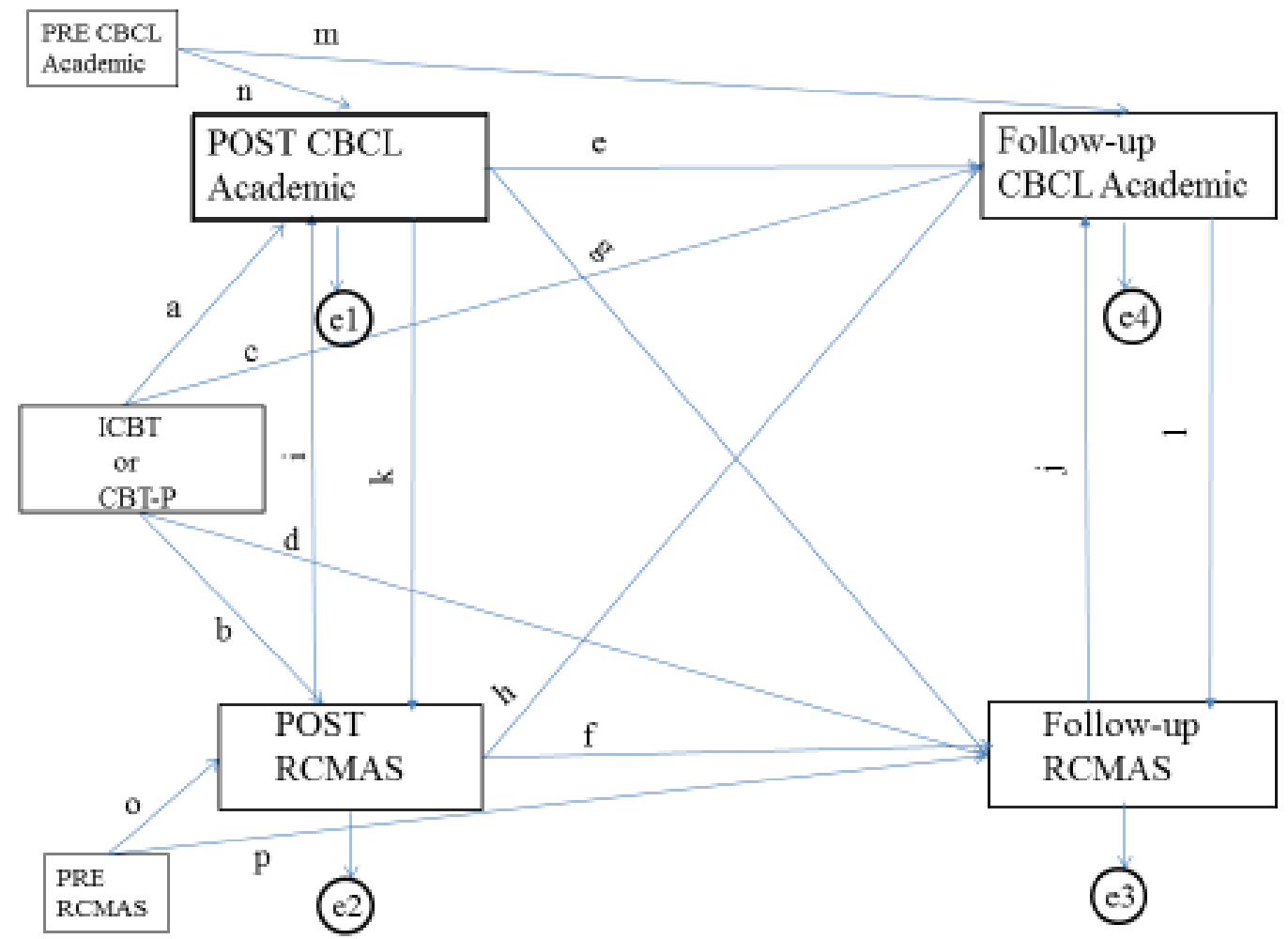

Note . RCMAS $=$ Revised Children's Manifest Anxiety; CBCL Academic $=$ CBCL

Academic Functioning Subscale; ICBT = Individual CBT treatment approach;

$\mathrm{CBT}+\mathrm{P}=\mathrm{CBT}$ with parental involvement. 
Figure 7. Conceptual Model for Social Functioning Lagged Effects

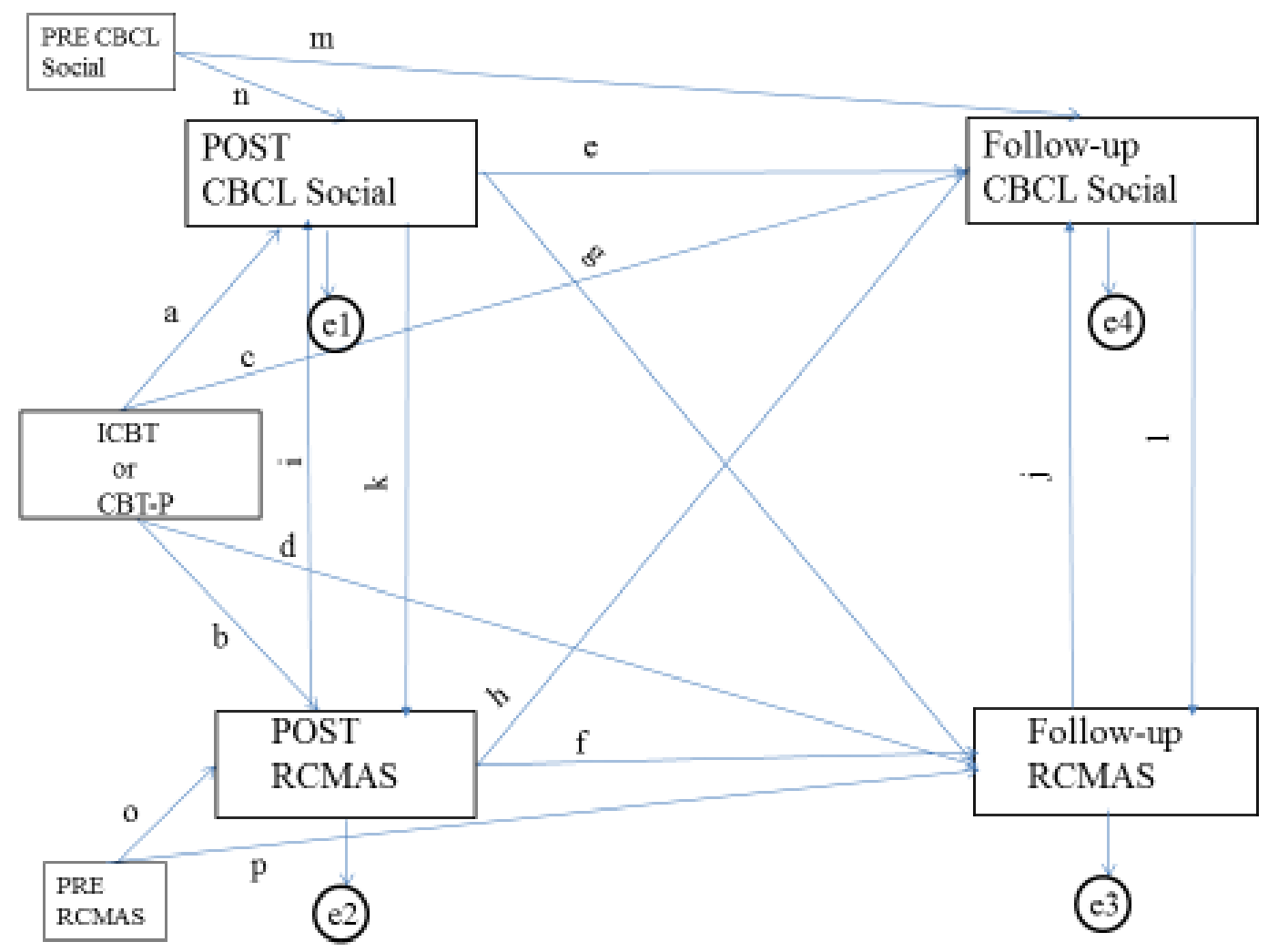

Note. RCMAS = Revised Children's Manifest Anxiety; CBCL Social = CBCL Social Functioning Subscale; ICBT= Individual CBT treatment approach; $\mathrm{CBT}+\mathrm{P}=\mathrm{CBT}$ with parental involvement. 
Figure 8. Academic Functioning Lagged Effects, Youth Model

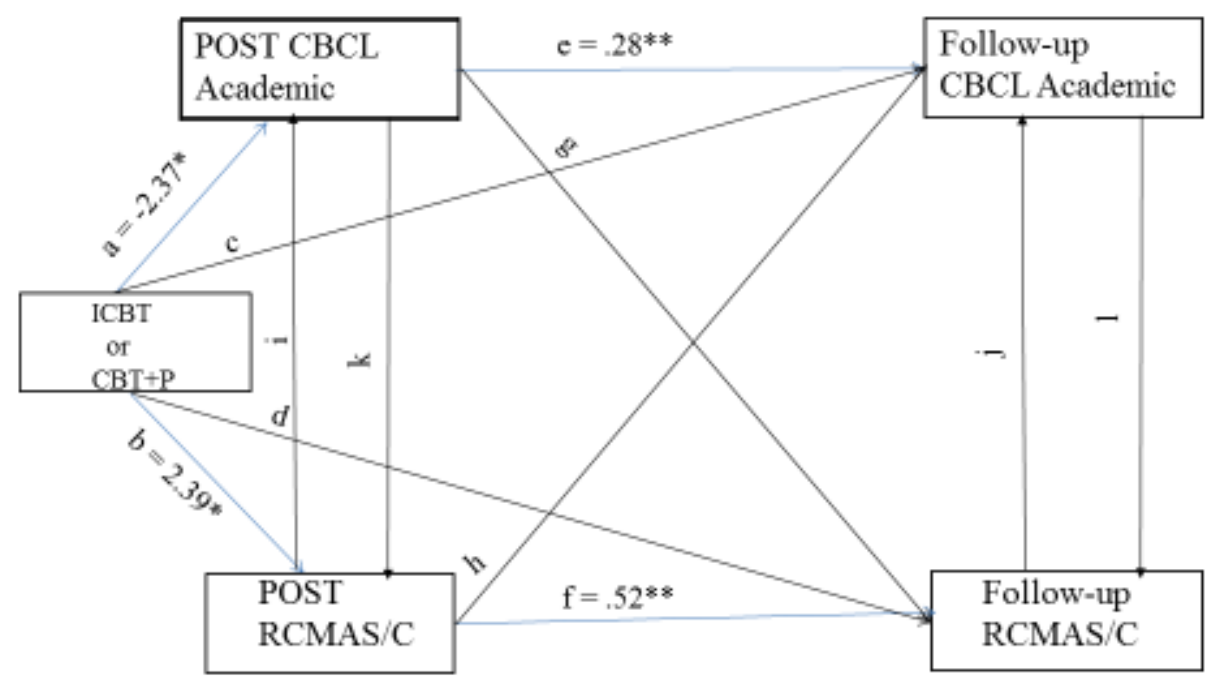

Note. RCMAS/C = Revised Children's Manifest Anxiety/Child Version; CBCL Academic = CBCL Academic Functioning Subscale; ICBT= Individual CBT treatment approach; $\mathrm{CBT}+\mathrm{P}=\mathrm{CBT}$ with parental involvement. 
Figure 9. Academic Functioning Lagged Effects, Parent Model

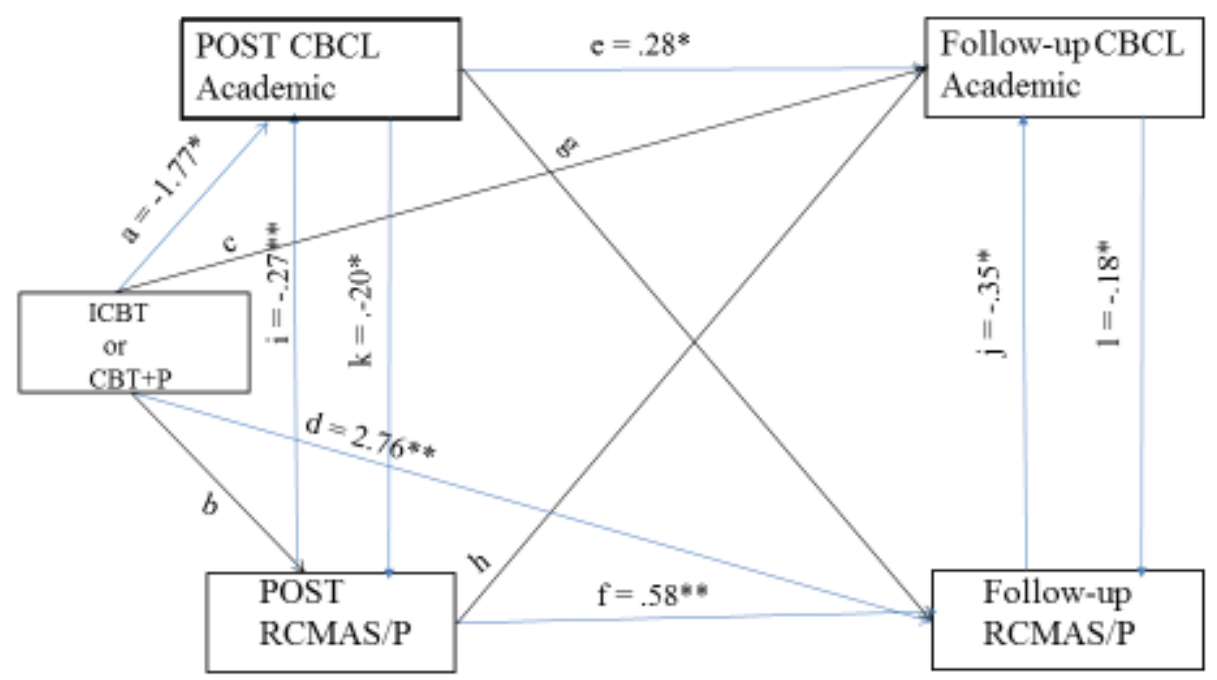

Note . RCMAS/P = Revised Children's Manifest Anxiety/Parent Version; CBCL Academic = CBCL Academic Functioning Subscale; ICBT= Individual CBT treatment approach; $\mathrm{CBT}+\mathrm{P}=\mathrm{CBT}$ with parental involvement. 
Figure 10. Social Functioning Lagged Effects, Youth Model

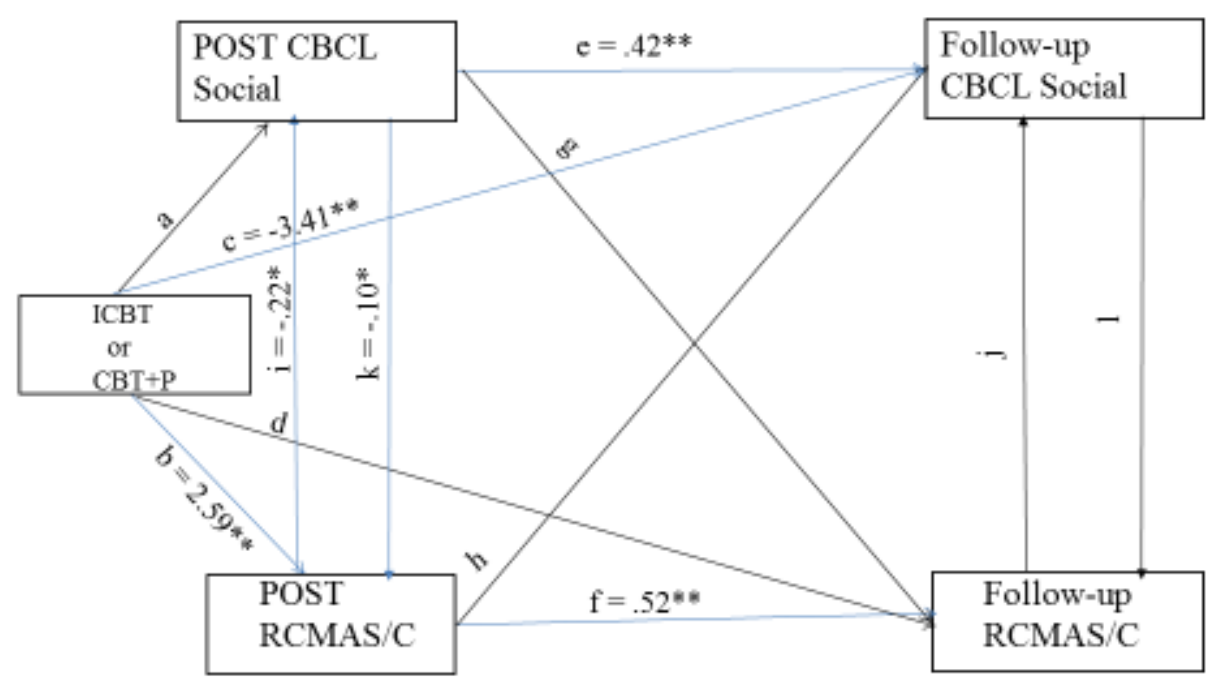

Note. RCMAS/C = Revised Children's Manifest Anxiety/Child Version; CBCL Social = CBCL Social Functioning Subscale; ICBT= Individual CBT treatment approach; $\mathrm{CBT}+\mathrm{P}=\mathrm{CBT}$ with parental involvement. 
Figure 11. Social Functioning Lagged Effects, Parent Model

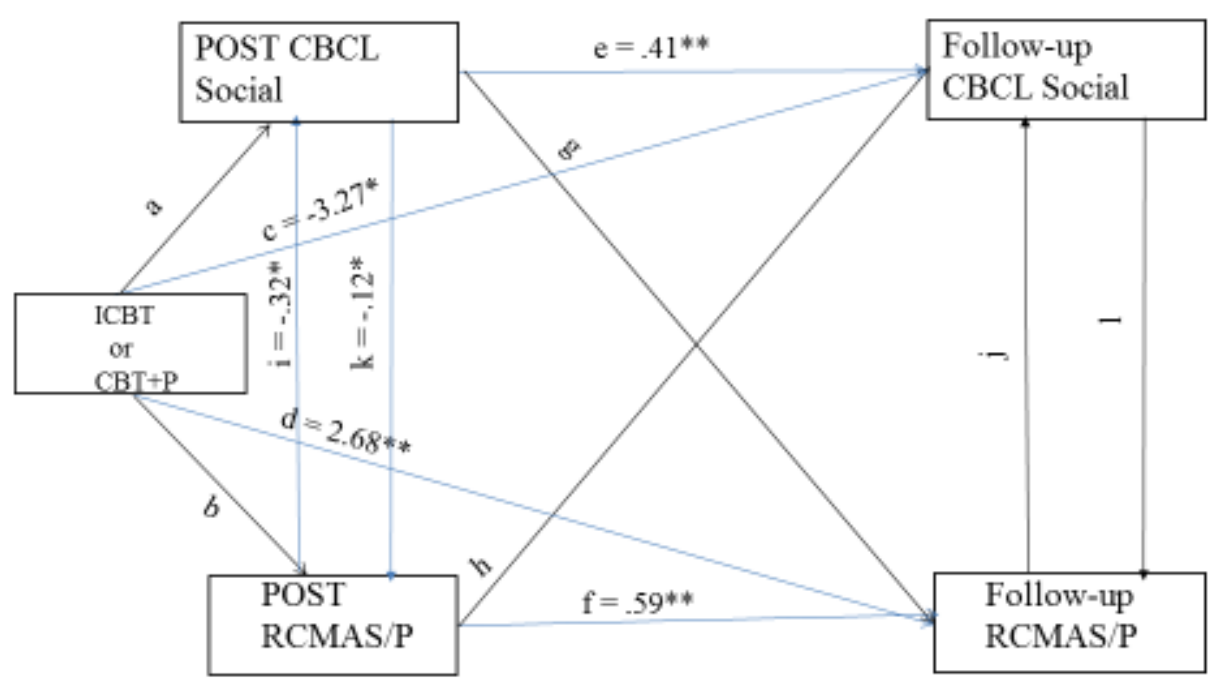

Note. RCMAS/P = Revised Children's Manifest Anxiety/Parent Version; CBCL Social = CBCL Social Functioning Subscale; ICBT= Individual CBT treatment approach; $\mathrm{CBT}+\mathrm{P}=\mathrm{CBT}$ with parental involvement. 


\section{LIST OF REFERENCES}

Achenbach, T. M., \& Rescorla, L. A. (2001). Manual for ASEBA school-age forms \& profiles. Research Center for Children, Youth, and Families, University of Vermont, Burlington.

Adler Nevo, G.W., Avery, D., Fiksenbaum, L., Kiss, A., Mendlowitz, S., Monga, S., \& Manassis, K. (2014). Eight years later: Outcomes of CBT-treated versus untreated anxious children. Brain and Behavior, 4,765-774. doi: 10.1002/brb3.274

Baker, C. N., \& Hoerger, M. (2012). Parental child-rearing strategies influence self regulation, socio-emotional adjustment, and psychopathology in early adulthood: Evidence from a retrospective cohort study. Personality and Individual Differences, 52(7), 800-805. http://dx.doi.org/10.1016/j.paid.2011.12.034

Barmish, A.J., \& Kendall, P.C. (2005). Should Parents Be Co-Clients in Cognitive Behavioral Therapy for Anxious Youth? Journal of Clinical Child \& Adolescent Psychology, 34(3), 569-581. http://dx.doi.org/10.1207/s15374424jccp3403_12

Barrett, P. M., Dadds, M. R., \& Rapee, R. M. (1996). Family treatment of childhood anxiety: A controlled trial. Journal of Consulting and Clinical Psychology, 64(2), 333-342. http://dx.doi.org/10.1037/0022-006X.64.2.333

Barrett, P. M. (1998). Evaluation of cognitive-behavioral group treatments for childhood anxiety disorders. Journal of Clinical Child Psychology, 27(4), 459-468. doi: $10.1207 / \mathrm{s} 15374424 \mathrm{jccp} 2704 \_10$

Barrett, P. M., Duffy, A.L., Dadds, M.R., \& Rapee, R.M. (2001). Cognitive-behavioral treatment of anxiety disorders in children: Long-term follow-up. Journal of Consulting and Clinical Psychology, 69(1), 135-141. doi: 10.1037//0022 006X.69.I.13

Beidel, D.C., Turner, S.M., Morris, T.L. (1995). A new inventory to assess childhood social anxiety and phobia: The Social Phobia and Anxiety Inventory for Children. Psychological Assessment, 7(1), 73-79. http://dx.doi.org/10.1037/1040 3590.7.1.73 
Beidel, D. C., Turner, S. M., \& Morris, T. L. (2000). Behavioral treatment of childhood social phobia. Journal of Consulting and Clinical Psychology, 68, 1072-1080. doi: 10.1037//0022-006X.68.6.1072

Beidel, D.C., Turner, S.M., Young, B., Paulson, A. (2005). Social effectiveness therapy for children: Three-year follow-up. Journal of Consulting and Clinical Psychology, 73(4), 721-725. http://dx.doi.org/10.1037/0022-006X.73.4.721

Beidel, D.C., Turner, S.M., Young, B.J. (2006). Social effectiveness therapy for children: Five years later. Behavior Therapy, 37(4), 416-425 http://dx.doi.org/10.1016/j.beth.2006.06.002

Benjamin, C.L., Harrison, J.P., Settipani, C.A., Brodman, D.M., \& Kendall, P.C. (2013). Anxiety and related outcomes in young adults 7 to 19 years after receiving treatment for child anxiety. Journal of Consulting and Clinical Psychology, 81, 865-876. http://dx.doi.org/10.1037/a0033048

Bittner, A., Egger, H.L., Erkanli, A., Costello, E.J., Foley, D.L. \&, Angold A. (2007). What do childhood anxiety disorders predict? Journal of Child Psychology and Psychiatry, 48,1174-1183. doi: 10.1111/j.1469-7610.2007.01812.x.

Bollen, K. \& Long, S. (1993). Testing structural equation models. Newbury Park: Sage.

Buckner, J.D., Schmidt, N.B., Lang, A.R., Small, J.W., Schlauch, R.C., \& Lewinsohn, P.M. (2008). Specificity of social anxiety disorder as a risk factor for alcohol and cannabis dependence. Journal of Psychiatry Research, 42(3), 230-239. doi:10.1016/j.jpsychires.2007.01.002

Buckner, J. D., \& Schmidt, N. B. (2009). Social anxiety disorder and marijuana use problems: The mediating role of marijuana effect expectancies. Depression and Anxiety, 26, 864-870. http://dx.doi.org/10.1002/da.20567

Calzada, E. J., Fernandez, Y., \& Cortes, D. E. (2010). Incorporating the cultural value of respeto into a framework of Latino parenting. Cultural Diversity \& Ethnic Minority Psychology, 16(1), 77-86. doi:10.1037/a0016071 
Cartwright-Hatton, S., Roberts, C., Chitsabesan, P., Fothergill, C., \& Harrington, R. (2004). Systematic review of the efficacy of cognitive behavior therapies for childhood and adolescent anxiety disorders. British Journal of Clinical Psychology, 43(4), 421-436. doi:10.1348/0144665042388928

Chorpita, B.F., Becker, K.D., \& Daleiden, E.L. (2007). Understanding the common elements of evidence-based practice: Misconceptions and clinical examples. Journal of the American Academy of Child and Adolescent Psychiatry, 46(5), 647-652. doi: 10.1097/chi.0b013e318033ff71

Creswell, C., \& Cartwright-Hatton, S. (2007). Family treatment of child anxiety: Outcomes, limitations and future directions. Clinical Child and Family Psychology Review, 10(3), 232-252. doi:http://dx.doi.org/10.1007/s10567-007 0019-3

Cobham, V. E., Dadds, M. R., \& Spence, S. H. (1998). The role of parental anxiety in the treatment of childhood anxiety. Journal of Consulting and Clinical Psychology, 66(6), 893-905. http://dx.doi.org/10.1037/0022-006X.66.6.893

Cobham, V. E., Dadds, M. R., Spence, S. H., \& McDermott, B. (2010). Parental anxiety in the treatment of childhood anxiety: A different story three years later. Journal of Clinical Child and Adolescent Psychology, 39(3), 410-420. http://dx.doi.org/10.1080/15374411003691719

Costello, E. J., Egger, H. L., Copeland, W., Erkanli, A., \& Angold, A. (2011). The developmental epidemiology of anxiety disorders, phenomenology, prevalence, and comorbidity. In Silverman, W. K., \& Fields, A. (2011). Anxiety disorders in children and adolescents: Research, assessment, and intervention, $2^{\text {nd }}$ edition. Cambridge, U. K.: Cambridge University Press.

Esbjørn, B.H., Reinholdt-Dunne, M.L., Nielsen, S.K., Smith, A.C., Breinholst, S., \& Leth, I. (2015). Exploring the effect of case formulation driven CBT for children with anxiety disorders: A feasibility study. Behavioural and Cognitive Psychotherapy, 43, 20-30. doi:10.1017/S1352465813000702. 
Enders, C. K. (2001). The impact of nonnormality on full information maximum likelihood estimation for structural equation models with missing data. Psychological Methods, 6(4), 352-370. http://dx.doi.org/10.1037/1082 989X.6.4.352

Erath, S.A., Flanagan, K.S. \& Bierman, K.L. (2007). Social anxiety and peer relations in early adolescence: Behavioral and cognitive factors. Journal of Abnormal Child Psychology, 35, 405-416. http://dx.doi.org/10.1007/s10802-007-9099-2

Ginsburg, G. S., Silverman, W. K., \& Kurtines, W. M. (1995). Family involvement in treating children with phobic and anxiety disorders: A look ahead. Clinical Psychology Review, 15, 457-473. doi: 10.1016/0272-7358(95)00026-L

Ginsburg, G. S., Grover, R. L., \& Ialongo, N. (2004). Parenting behaviors among anxious and non-anxious mothers: Relation with concurrent and long-term child outcomes. Child \& Family Behavior Therapy, 26(4), 23-41. http://dx.doi.org/10.1300/J019v26n04_02

Ginsburg, G. S., Becker, E. M., Keeton, C. P., Sakolsky, D., Piacentini, J., Albano, A. M., . . Kendall, P. C. (2014). Naturalistic follow-up of youths treated for pediatric anxiety disorders. JAMA Psychiatry, 71(3), 310-318. http://dx.doi.org.ezproxy.fiu.edu/10.1001/jamapsychiatry.2013.4186

Hill, R. M., Castellanos, D. A., \& Pettit, J. W. (2011). Suicidal behavior and anxiety in children and adolescents: A review of the past 20 years. Clinical Psychology Review, 31, 1133-1144. doi: 10.1016/j.cpr.2011.07.008

Hudson, J. L., \& Rapee, R. M. (2005). Psychopathology and the family. New York: Elsevier Science.

Inderbitzen, H.M., Walters, K.S., \& Bukowski, A.L. (1997). The role of social anxiety in adolescent peer relations: Differences among sociometric status groups and rejected subgroups. Journal of Clinical Child Psychology, 26, 338-348. http://dx.doi.org.ezproxy.fiu.edu/10.1207/s15374424jccp2604_2

Jaccard, J. \& Wan (1996). LISREL analyses of interaction effects in multiple regression. Newbury Park: Sage. 
Jackson, D. (2003). Revisiting sample size and number of parameter estimates: Some support for the null hypothesis. Structural Equation Modeling, 10, 128-141.

Johnson, L.E., \& Greenberg, M.T. (2013). Parenting and early adolescent internalizing: The importance of teasing apart anxiety and depressive symptoms. Journal of Early Adolescence, 33(2), 201-226. doi:10.1177/0272431611435261.

Kendall, P. C. (1994). Treating anxiety disorders in children: Results of a randomized clinical trial. Journal of Consulting and Clinical Psychology, 62(1), 100-110. http://dx.doi.org/10.1037/0022-006X.62.1.100

Kendall, P.C., Southam-Gerow, M.A. (1996). Long-term follow-up of a cognitive behavioral therapy for anxiety-disordered youth. Journal of Consulting and Clinical Psychology, 64(4), 724-730. http://dx.doi.org/10.1037/0022 006X.64.4.724

Kendall, P. C., Flannery-Schroeder, E., Panichelli-Mindel, S. M., Southam-Gerow, M., Henin, A., \& Warman, M. (1997). Therapy for youth with anxiety disorders: A second randomized clinical trial. Journal of Consulting and Clinical Psychology, 65(3), 366-380. http://dx.doi.org/10.1037/0022-006X.65.3.366

Kendall, P.C., Safford, S., Flannery-Schroeder, E., \& Webb, A. (2004). Child anxiety treatment: Outcomes in adolescence and impact on substance use and depression at 7.4-Year Follow-Up. Journal of Consulting and Clinical Psychology, 72(2), 276-287. http://dx.doi.org/10.1037/0022-006X.72.2.276

Kendall, P. C., Hudson, J. L., Gosch, E., Flannery-Schroeder, E., \& Suveg, C. (2008). Cognitive behavioral therapy for anxiety disordered youth: A randomized clinical trial evaluating child and family modalities. Journal of Consulting and Clinical Psychology, 76(2), 282 297. http://dx.doi.org/10.1037/0022-006X.76.2.282

Kessler, R. C., Foster, M. P. H., Saunders, W. B., \& Stang, P. E. (1995). Social consequences of psychiatric disorders I: educational attainment. American Journal of Psychiatry, 152, 71026-71032. 
Kingery, J. N., Erdley, C. A., Marshall, K. C., Whitaker, K. G., \& Reuter, T. R. (2010). Peer experiences of anxious and socially withdrawn youth: An integrative review of the developmental and clinical literature. Clinical Child and Family Psychology Review, 13(1), 91-128. http://dx.doi.org/10.1007/s10567-009-0063-2

King, G., Honaker, J., Joseph, A. \& Scheve, K. (2001). Analyzing incomplete political science data: An alternative algorithm for multiple imputation. American Political Science Review, 95, 49-69.

Kovacs M. (1992). Children's Depression Inventory Manual. North Tonawanda, NY: Multi Health Systems, Inc.

La Greca, A.M., \& Lopez, N. (1998). Social anxiety among adolescents: Linkages with peer relations and friendships. Journal of Abnormal Child Psychology, 26, 83-94. http://dx.doi.org.ezproxy.fiu.edu/10.1023/A:1022684520514

Langley, A.K., Falk, A., Peris, T., Wiley, J.F., Kendall, P.C., ... Piacentini, J. (2014) The child anxiety impact scale: Examining parent- and child-reported impairment in child anxiety disorders. Journal of Clinical Child \& Adolescent Psychology, 43(4), 579-591. doi: 10.1080/15374416.2013.817311

Langley, A. K., Bergman, R. L., McCracken, J., \& Piacentini, J. C. (2004). Impairment in childhood anxiety disorders: Preliminary examination of the Child Anxiety Impact Scale Parent Version. Journal of Child and Adolescent Psychopharmacology, 14, 105-114. http://dx.doi.org.ezproxy.fiu.edu/10.1089/104454604773840544

Lewinsohn, P.M., Holm-Denoma, J.M., Small, J.W., Seeley, J.R., \& Joiner, T.E. (2008). Separation anxiety disorder in childhood as a risk factor for future mental illness. Journal of the American Academy of Child and Adolescent Psychiatry, 47, 548555. doi: 10.1097/CHI.0b013e31816765e7

Manassis, K., Avery, D., Butalia, S., \& Mendlowitz, S. (2004). Cognitive-behavioral therapywith childhood anxiety disorders: Functioning in adolescence. Depression and Anxiety, 19(4), 209-216. http://dx.doi.org/10.1002/da.10133 
Manassis, K., Lee, T. C., Bennett, K., Zhao, X. Y., Mendlowitz, S., Duda, S... Wood, J. J. (2014). Types of parental involvement in CBT with anxious youth: A preliminary meta analysis. Journal of Consulting and Clinical Psychology. http://dx.doi.org/10.1037/a0036969

Mathew, A.R., Pettit, J.W., Lewinsohn, P.M., Seeley, J.R., \& Roberts, R.E. (2011). Comorbidity between major depressive disorder and anxiety disorders: Shared etiology or direct causation? Psychological Medicine, 41(10), 2023-2034.

Mendlowitz, S. L., Manassis, K., Bradley, S., Scapillato, D., Miezitis, S., \& Shaw, B. F. (1999).Cognitive-behavioral group treatments in childhood anxiety disorders: The role of parental involvement. Journal of the American Academy of Child \& Adolescent Psychiatry, 38(10), 1223-1229. http://dx.doi.org/10.1097/00004583 199910000-00010

Monroe, C., Borzi, M. G., \& Burrell, R. D. (1992). Communication apprehension among high school dropouts. The School Counselor, 39, 273-280. retrieved from http://ezproxy.fiu.edu/login?url=http://search.proquest.com.ezproxy.fiu.edu/docv ew/61156038? accountid=10901

Muthén, L.K., \& Muthén, B.O. (2011). Mplus User's guide: Vol. 7, Los Angeles, CA: Muthén \& Muthén

Nail, J. E., Christofferson, J., Ginsburg, G. S., Drake, K., Kendall, P. C., McCracken, J. T., ... Sakolsky, D. (2015). Academic Impairment and Impact of Treatments Among Youth with Anxiety Disorders. Child and Youth Care Forum, 44(3), 327 342. doi:10.1007/s10566-014-9290-x

Pine, D.S., Cohen, P., Gurley, D., Brook, J., \& Ma, Y. (1998). The risk of early adulthood anxiety and depressive disorders in adolescents with anxiety and depressive disorders. Archives of General Psychiatry, 55, 56-64. doi:10.1001/archpsyc.55.1.56

Reynolds, C. R., \& Richmond, B. O. (1978). What I think and feel: A revised measure of children's manifest anxiety. Journal of Abnormal Child Psychology, 6, 271-280. doi: 10.1007/BF00919131 
Rapee, R. M. (1997). Potential role of childrearing practices in the development of anxiety and depression. Clinical psychology review, 17(1), 47-67.

doi:10.1016/S0272-7358(96)00040-2

Saavedra, L.M., Silverman, W.K., Morgan-Lopez, A.A., \& Kurtines, W.M. (2010). Cognitive behavioral treatment for childhood anxiety disorders: long-term effects on anxiety and secondary disorders in young adulthood. Journal of Child Psychology and Psychiatry 51, 924-934. doi: 10.1111/j.1469-7610.2010.02242.x

Settipani, C.A., \& Kendall, P.C. (2013). Social functioning in youth with anxiety disorders: Association with anxiety severity and outcomes from cognitive behavioral therapy. Child Psychiatry and Human Development 44(1), 1-18. doi:10.1007/s10578-012-0307-0

Schuldermann, S., \& Schuldermann, E. (1988). Questionnaire for Children and Youth (CRPBI-30) Unpublished manuscript, University of Manitoba, Winnipeg

Shirneshan, E., Bailey, J., Relyea, G., Franklin, B.E., Solomon, D.K., \& Brown, L.M. (2013). Incremental direct medical expenditures associated with anxiety disorders for the U.S. adult population: Evidence from the medical expenditure panel survey. Journal of Anxiety Disorders, 27(7), 720-727. doi: 10.1016/j.janxdis.2013.09.009

Silverman, W. K., \& Albano, A. M. (1996). Anxiety Disorders Interview Schedule for Children-IV (Child and Parent Versions). San Antonio, TX: Psychological Corporation.

Silverman, W.K., \& Kurtines, W.K. (1996). Childhood anxiety and phobic disorders: A pragmatic perspective. New York: Plenum Press

Silverman, W. K., Kurtines, W. M., Ginsburg, G. S., Weems, C. F., Lumpkin, P. W., \& Carmichael, D. H. (1999). Treating anxiety disorders in children with group cognitive behavioral therapy: A randomized clinical trial. Journal of Consulting and Clinical Psychology, 67, 995-1003. http://dx.doi.org/10.1037/0022 006X.67.6.995 
Silverman, W. K., Kurtines, W. M., Ginsburg, G. S., Weems, C. F., Rabian, B., \& Serafini, L. T. (1999). Contingency management, self-control, and education support in the treatment of childhood phobic disorders: A randomized clinical trial. Journal of Consulting and Clinical Psychology, 67, 675-687. doi: 10.1037/0022-006X.67.5.675

Silverman, W. K., Saavedra, L. M., \& Pina, A. A. (2001). Test-retest reliability of anxiety symptoms and diagnoses with the Anxiety Disorders Interview Schedule for DSM-IV: Child and Parent Versions. Journal of the American Academy of Child and Adolescent Psychiatry, 40(8), 937-944. http://dx.doi.org/10.1097/00004583 200108000-00016

Silverman, W. K., Pina, A. A., \& Viswesvaran, C. (2008). Evidence-based psychosocial treatments for phobic and anxiety disorders in children and adolescents. Journal of Clinical Child and Adolescent Psychology, 37, 105-130. doi: 10.1080/15374410701817907.

Silverman, W. K., Kurtines, W. M., Jaccard, J., \& Pina, A. A. (2009). Directionality of change in youth anxiety treatment involving parents: An initial examination. Journal of Consulting and Clinical Psychology, 77(3), 474-485. http://dx.doi.org/10.1037/a0015761

Siqueland, L., Kendall, P. C., \& Steinberg, L. (1996). Anxiety in children: Perceived family environments and observed family interactions. Journal of Clinical Child Psychology, 25(2), 225-237. http://dx.doi.org.ezproxy.fiu.edu/10.1207/s15374424jccp2502_12

Thulin, U., Svirsky, L., Serlachius, E., Andersson, G., \& Ost, L. (2014). The effect of parent involvement in the treatment of anxiety disorders in children: A meta analysis. Cognitive Behavior Therapy, 43(3), 185-200. doi: 10.1080/16506073.2014.923928

Van Ameringen, M., Mancini, C., \& Farvolden, P. (2003). The impact of anxiety disorders on educational attainment. Journal of Anxiety Disorders, 17, 561-571. doi: 10.1016/S08876185(02)00228-1 
Varela, E.R., \& Biggs, B.K. (2006). Reliability and validity of the Revised Children's Manifest Anxiety Scale (RCMAS) across samples of Mexican, Mexican American, and European American children: a preliminary investigation. Anxiety, Stress, and Coping, 19, 67-80. doi: 10.1080/10615800500499727

Varela, R. E., \& Hensley-Maloney, L. (2009). The influence of culture on anxiety in Latino youth: A review. Clinical Child and Family Psychology Review, 12(3), 21733. doi:10.1007/s 10567-009-0044-5

Verduin, T.L., \& Kendall, P.C. (2008). Peer Perceptions and Liking of Children with Anxiety Disorders. Journal of Abnormal Child Psychology, 36(4), 459-469. http://dx.doi.org/10.1007/s10802-007-9192-6

Vernberg, E.M., Abwender, D.A., Ewell, K.K., \& Beery, S.H. (1992). Social anxiety and peer relationships in early adolescence: A prospective analysis. Journal of Clinical Child Psychology, 21, 189-196. http://dx.doi.org.ezproxy.fiu.edu/10.1207/s15374424jccp2102_11

Walczak, M., Hoff Esbjorn, B., Breinholst, S., \& Reinholdt-Dunne, M.L. (2016). Parental involvement in cognitive behavior therapy for children with anxiety disorders: 3 year follow-up. Child Psychiatry and Human Development, 47. 1-11. doi:10.1007/s10578-016-0671-2

Walkup, J.T., Albano, A.M., Piacentini, J., Birmaher, B., Compton, S.N., Sherrill, J.T., \& Kendall, P.C. (2008). Cognitive Behavioral Therapy, Sertraline, or a Combination in childhood anxiety. The New England Journal of Medicine, 359(26), 2753 2766. http://doi.org/10.1056/NEJMoa0804633

Weems, C. F., Taylor, L. K., Costa, N. M., Marks, A. B., Romano, D. M., Verrett, S. L., et al. (2009). Effect of a school-based test anxiety intervention in ethnic minority youth exposed to Hurricane Katrina. Journal of Applied Developmental Psychology, 218-226. doi:10.1016/j.appdev.2008.11.005.

Wood, J. J., McLeod, B. D., Sigman, M., Hwang, W., \& Chu, B. C. (2003). Parenting and childhood anxiety: Theory, empirical findings, and future directions. Journal of Child Psychology and Psychiatry, 44(1), 134-151. http://dx.doi.org.ezproxy.fiu.edu/10.1111/1469-7610.00106 
Wood, J.J. (2006). Effect of anxiety reduction on children's school performance and social adjustment. Developmental Psychology, 42, 345-349. doi: 10.1037/0012 1649.42.2.345

Wood, J. J., Piacentini, J. C., Southam-Gerow, M., Chu, B. C., \& Sigman, M. (2006). Family cognitive behavioral therapy for child anxiety disorders. Journal of the American Academy of Child \& Adolescent Psychiatry, 45(3), 314-321. http://dx.doi.org/10.1097/01.chi.0000196425.88341.b0

Wood, J. J., McLeod, B. D., Piacentini, J. C., \& Sigman, M. (2009). One-year follow-up of family versus child CBT for anxiety disorders: Exploring the roles of child age and parental intrusiveness. Child Psychiatry and Human Development, 40(2), 301-316. http://dx.doi.org/10.1007/s10578-009-0127-z

Wothke, W. (2000). Longitudinal and multi-group modeling with missing data. In Little, T.D., Schnabel, K.U., \& Baumert, J. (Eds.). Modeling longitudinal and multilevel data. Lawrence Erlbaum, Mahwah, N.J. 


\section{APPENDICES}

Please print CHILD BEHAVIOR CHECKLIST FOR AGES 6-18 $\overline{\text { Foroffice use or }}$

\begin{tabular}{|c|c|c|c|}
\hline $\begin{array}{l}\text { CHILD'S } \\
\text { UULL } \\
\text { VAME }\end{array}$ & \multicolumn{2}{|l|}{ תיר איח } & \multirow{3}{*}{$\begin{array}{l}\text { PARENTS' USUAL TYPE OF WORK, even if not working now. (Ple } \\
\text { be specific - for example, auto mechanic, high school teacher, homem } \\
\text { laborer, lathe operator, shoe salesman, amy sergeant.) } \\
\text { FATHER'S } \\
\text { TYPE OF WORK } \\
\text { MOTHER'S } \\
\text { TYPE OF WORK } \\
\text { THIS FORM FLLLE OUT BY: (print your full name) }\end{array}$} \\
\hline $\begin{array}{l}\text { CHILD'S GENDER } \\
\square \text { Boy } \square \text { Girt }\end{array}$ & CHILD'S AGE & $\begin{array}{l}\text { CHILD'S ETHNIC GROUP } \\
\text { OR RACE }\end{array}$ & \\
\hline TODAY'S DATE & Yr. & $\begin{array}{ll}\text { CHILD'S BIRTHDATE } \\
\text { Mo.___ Date___ Yr. }\end{array}$ & \\
\hline $\begin{array}{l}\text { OT ATTENDING } \\
\text { CHOOL } \square\end{array}$ & \multicolumn{2}{|c|}{$\begin{array}{l}\text { Please fill out this form to reflect your view of the } \\
\text { child's behavior even if other people might not } \\
\text { agree. Feel free to print additional comments } \\
\text { beside each item and in the space provided on } \\
\text { page 2. Be sure to answer all items. }\end{array}$} & $\begin{array}{l}\text { Your gender. } \square \text { Male } \quad \square \text { Fernale } \\
\text { Your relation to the child: } \\
\square_{\text {Biological Parent }} \square_{\text {Step Parent }} \square \text { Grandparent } \\
\square \text { Adoptive Parent } \quad \square \text { Foster Parent }\end{array}$ \\
\hline
\end{tabular}

I. Please list the sports your child most likes Compared to others of the same to take part in. For example: swimming. baseball, skating, skate boarding, bike age, how well does he/she do riding, fishing, etc.

$\square$ None

he/she spend in each? each one?

a.

Less More

Than Than Don't Below Above Do

b.

$\square \square \square \square$

$\square \square \square \square$

c.

$\square \quad \square \quad \square \quad \square$

II. Please list your child's favorite hobbies, activities, and games, other than sports. For example: stamps, dolls, books, piano crafts, cars, computers, singing, etc. (Do not include listening to radio or TV.)

$\square$ None

Compared to others of the same age, about how much time does he/she spend in each?

Loss

Average Average Average $\mathrm{Kn}$

a.

Average Average Than Don't

$\square \square \square$

-

$\begin{array}{llll}\square & \square & \square & \square\end{array}$

b.

$\begin{array}{llll}\square & \square & \square & \square\end{array}$

c.

$\square \quad \square \quad \square \quad \square$

口

$\square \quad[$

III. Please list any organizations, clubs, teams,

Compared to others of the same or groups your child belongs to. age, how active is he/she in each?

$\square$ None

a.

$\begin{array}{lll}\text { Less } & \text { More Don't } \\ \text { Active Average Active } & \text { Know }\end{array}$

b.

Active Average Active Know

b.

c.

口 $0 \quad 0 \quad 0$

IV. Please list any jobs or chores your child has. For example: paper route, babysitting, making bed, working in store, etc. (Include both paid

$$
\text { Q 口 Q }
$$

Compared to others of the same age, how well does he/she carry and unpaid jobs and chores.)

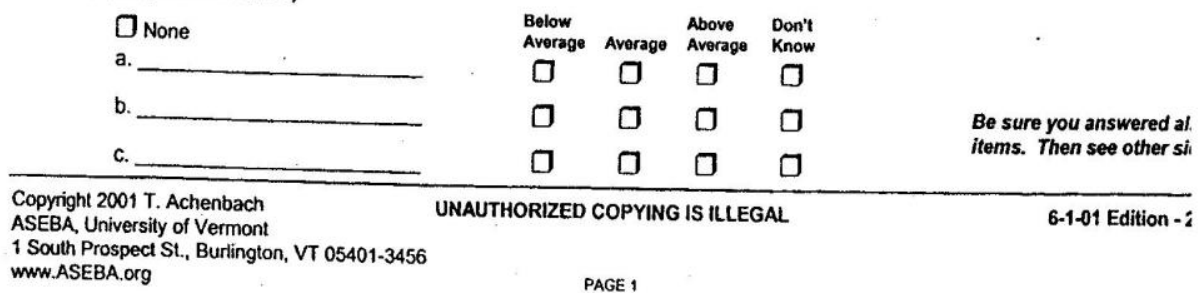


Please print. Be sure to answer all items.

v. 1. About how many close friends does your child have? (Do not include brothers \& sisters)

$$
\square_{\text {None }} \square_{1} \square_{2} \text { or } 3 \quad \square_{4} \text { ormore }
$$

2. About how many times a week does your child do things with any friends outside of regular school hours?

\begin{tabular}{llll} 
(Do not include brothers \& sisters) & $\square$ Less than 1 & $\square$ & or $2 \quad \square$ or more \\
\hline Vl. Compared to others of his/her age, how well does your child: & & & \\
a. Get along with his/her brothers \& sisters? & $\square$ & $\square$ Average & Better \\
b. Get along with other kids? & $\square$ & $\square$ & $\square$ \\
c. Behave with his/her parents? & $\square$ & $\square$ & $\square$ \\
d. Play and work alone? & $\square$ & $\square$ & $\square$ \\
\hline
\end{tabular}

VII. 1. Performance in academic subjects. $\quad \square$ Does not attend school because

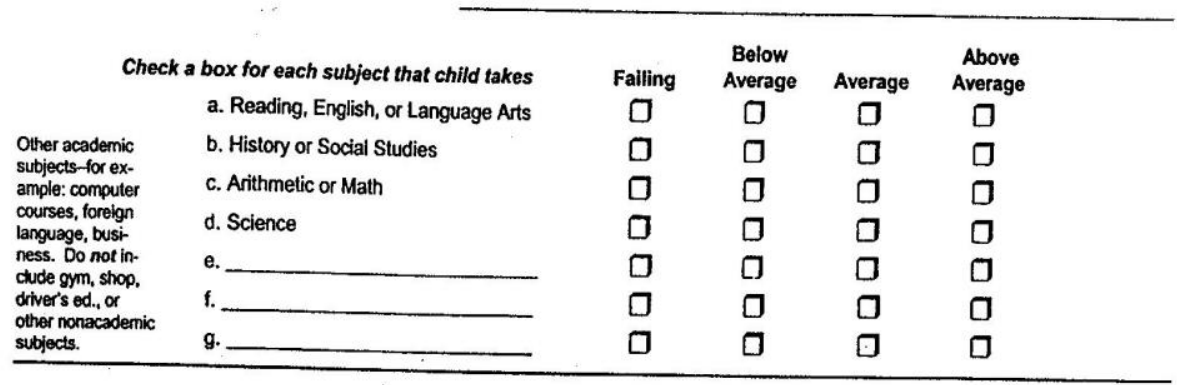

2. Does your child receive special education or remedial services or attend a special class or special school?

$\square$ No $\square$ Yes-kind of services, class, or school:

3. Has your child repeated any grades? $\square$ No $\square$ Yes-grades and reasons:

4. Has your chlld had any academic or other problems in school? $\square$ No $\square$ Yes-please describe:

When did these problems start?

Have these problems ended? $\square$ No $\square$ Yes-when?

Does your child have any illness or disability (either physical or mental)? $\square_{\text {No }} \square$ Yes-please describe:

What concerns you most about your child?

Please describe the best things about your child. 
$\underline{\text { RCMAS - youth report }}$

Instructions: Read each question carefully. Put a circle around the word YES if you think it is true about you. Put a circle around the word NO if you think it is not true about you.

1. I have trouble making up my mind. yes no

2. I get nervous when things do not go the right way. yes no

3. Others seem to do things easier than I can. yes no

4. I like everyone I know. $\quad$ yes No

5. Often I have trouble getting my breath. $\quad$ yes $\quad$ No

6. I worry a lot of the time. yes no

7. I am afraid of a lot of things. yes no

8. I am always kind. yes no

9. I get mad easily. $\quad$ yes no

10. I worry about what my parents will say to me. $\quad$ yes no

11. I feel that others do not like the way I do things. yes no

12. I always have good manners. $\quad$ yes no

13. It is hard for me to get to sleep at night. $\quad$ yes no

14. I worry about what other people think about me. $\quad$ yes no

15. I feel alone even when there are people with me. $\quad$ yes no

16. I am always good. $\quad$ yes no

17. Often I feel sick in my stomach. $\quad$ yes no

18. My feelings get hurt easily. yes no 
19. My hands feel sweaty.

20. I am always nice to everyone.

yes no

21. I am tired a lot.

yes no

22. I worry about what is going to happen.

yes no

23. Other children are happier than I.

yes no

24. I tell the truth every single time.

yes no

25. I have bad dreams.

yes no

26. My feelings get hurt easily when I am fussed at.

yes no

27. I feel someone will tell me I do things the wrong way.

yes no

28. I never get angry.

yes no

29. I wake up scared some of the time.

yes no

30. I worry when I go to bed at night.

yes no

31. It is hard for me to keep my mind on my schoolwork.

yes no

32. I never say things I shouldn't.

yes no

33. I wiggle in my seat a lot.

yes no

34. I am nervous.

yes no

35. A lot of people are against me.

yes no

36. I never lie.

yes no

37. I often worry about something bad happening to me.

yes no 


\section{$\underline{\text { RCMAS - parent report }}$}

Instructions: Put a circle around the word YES if you think it is true about your child. Put a circle around the word NO if you think it is not true about your child.

1. My child has trouble making up his/her mind. yes no

2. My child gets nervous when things do not go the right way. yes No

3. Others seem to do things easier than my child can. yes no

4. My child likes everyone he/she knows. yes no

5. Often my child has trouble getting his/her breath. yes no

6. My child worries a lot of the time. yes no

7. My child is afraid of a lot of things. yes no

8. My child is always kind. yes no

9. My child gets mad easily. yes no

10. My child worries about what I will say to him/her. yes no

11. My child feels that others do not like the way he/she does things. yes no

12. My child always has good manners. yes no

13. It is hard for my child to get to sleep at night. yes no

14. My child worries about what other people think about him/her. $\quad$ yes no

15. My child feels alone even when there are people with him/her. $\quad$ yes no

16. My child is always good. yes no

17. Often my child feels sick in his/her stomach. yes no

18. My child's feelings get hurt easily. yes no 
19. My child's hands feel sweaty. $\quad$ yes no

20. My child is always nice to everyone. yes no

21. My child is tired a lot. yes no

22. My child worries about what is going to happen. yes no

23. Other children are happier than my child. yes no

24. My child tells the truth every single time. $\quad$ yes no

25. My child has bad dreams. yes no

26. My child's feelings get hurt easily when he/she is fussed at. $\quad$ yes no

27. My child feels someone will tell him/her that he/she does things the yes no wrong way.

28. My child never gets angry. $\quad$ yes no

29. My child wakes up scared some of the time. yes no

30. My child worries when he/she goes to bed at night. yes no

31. It is hard for my child to keep his/her mind on his/her schoolwork. yes no

32. My child never says things he/she shouldn't. yes no

33. My child wiggles in his/her seat a lot. $\quad$ yes no

34. My child is nervous. $\quad$ yes no

35. A lot of people are against my child. $\quad$ yes no

36. My child never lies. $\quad$ yes no

37. My child often worries about something bad happening to him/her. yes no 
Children's Depression Inventory (CDI)

KIDS SOMETIMES HAVE DIFFERENT FEELINGS AND IDEAS.

THIS FORM LISTS THE FEELINGS AND IDEAS IN GROUPS. FROM EACH GROUP, PICK ONE SENTENCE THAT DESCRIBES YOU BEST FOR THE PAST TWO WEEKS. AFTER YOU PICK A SENTENCE FROM THE FIRST GROUP, GO ON TO THE NEXT GROUP.

THERE IS NO RIGHT ANSWER OR WRONG ANSWER. JUST PICK THE SENTENCE THAT BEST DESCRIBES THE WAY YOU HAVE BEEN RECENTLY. PUT A MARK LIKE THIS $X$ NEXT TO YOUR ANSWER. PUT THE MARK ON THE LINE NEXT TO THE SENTENCE THAT YOU PICK.

HERE IS AN EXAMPLE OF HOW THIS FORM WORKS. TRY IT. PUT A MARK NEXT TO THE SENTENCE THAT DESCRIBES YOU BEST.

EXAMPLE:

\begin{tabular}{l} 
I READ BOOKS ALL THE TIME \\
\hline I READ BOOKS ONCE IN A WHILE \\
I NEVER READ BOOKS
\end{tabular}

REMEMBER, PICK OUT THE SENTENCES THAT DESCRIBE YOUR FEELINGS AND IDEAS IN THE PAST TWO WEEKS.

1. I AM SAD ONCE IN A WHILE I AM SAD MANY TIMES I AM SAD ALL THE TIME

2. _ _ NOTHING WILL EVER WORK OUT FOR ME I AM NOT SURE IF THINGS WILL WORK OUT FOR ME THINGS WILL WORK OUT FOR ME O.K.

3. _ I DO MOST THINGS O.K. I DO MANY THINGS WRONG I DO EVERYTHING WRONG

4. _ I HAVE FUN IN MANY THINGS I HAVE FUN IN SOME THINGS NOTHING IS FUN AT ALL

5. I AM BAD ALL THE TIME I AM BAD MANY TIMES I AM BAD ONCE IN A WHILE 
6. I THINK ABOUT BAD THINGS HAPPENING TO ME ONCE IN A WHILE I WORRY THAT BAD THINGS WILL HAPPEN TO ME I AM SURE THAT TERRIBLE THINGS WILL HAPPEN TO ME

7. I HATE MYSELF I DO NOT LIKE MYSELF I LIKE MYSELF

8. ALL BAD THINGS ARE MY FAULT

- MANY BAD THINGS ARE MY FAULT
BAD THINGS ARE NOT USUALLY MY FAULT

9. __ I DO NOT THINK ABOUT KILLING MYSELF I THINK ABOUT KILLING MYSELF BUT I WOULD NOT DO IT I WANT TO KILL MYSELF

10. I FEEL LIKE CRYING EVERYDAY I FEEL LIKE CRYING MANY DAYS I FEEL LIKE CRYING ONCE IN A WHILE

11. _ THINGS BOTHER ME ALL THE TIME THINGS BOTHER ME MANY TIMES THINGS BOTHER ME ONCE IN A WHILE

12. _ I LIKE BEING WITH PEOPLE I DO NOT LIKE BEING WITH PEOPLE MANY TIMES I DO NOT WANT TO BE WITH PEOPLE AT ALL

13. I CANNOT MAKE UP MY MIND ABOUT THINGS IT IS HARD TO MAKE UP MY MIND ABOUT THINGS I MAKE UP MY MIND ABOUT THINGS EASILY

14. I LOOK O.K. THERE ARE SOME BAD THINGS ABOUT MY LOOKS I LOOK UGLY 
15. I HAVE TO PUSH MYSELF ALL THE TIME TO DO MY SCHOOLWORK I HAVE TO PUSH MYSELF MANY TIMES TO DO MY SCHOOLWORK DOING SCHOOLWORK IS NOT A BIG PROBLEM

16. I HAVE TROUBLE SLEEPING EVERY NIGHT I HAVE TROUBLE SLEEPING MANY NIGHTS I SLEEP PRETTY WELL

17. I AM TIRED ONCE IN A WHILE I AM TIRED MANY DAYS

I I AM TIRED ALL THE TIME

18. MOST DAYS I DO NOT FEEL LIKE EATING

— MANY DAYS I DO NOT FEEL LIKE EATING

_ I EAT PRETTY WELL

19. I DO NOT WORRY ABOUT ACHES AND PAINS I WORRY ABOUT ACHES AND PAINS MANY TIMES I WORRY ABOUT ACHES AND PAINS ALL THE TIME

20. I DO NOT FEEL ALONE I FEEL ALONE MANY TIMES I FEEL ALONE ALL THE TIME

21. I NEVER HAVE FUN AT SCHOOL I HAVE FUN AT SCHOOL ONLY ONCE IN A WHILE I HAVE FUN AT SCHOOL MANY TIMES

22. I HAVE PLENTY OF FRIENDS I HAVE SOME FRIENDS BUT I WISH I HAD MORE I DO NOT HAVE ANY FRIENDS

23. MY SCHOOLWORK IS ALRIGHT MY SCHOOLWORK IS NOT AS GOOD AS BEFORE I DO VERY BADLY IN SUBJECTS I USED TO BE GOOD IN

24. I CAN NEVER BE AS GOOD AS OTHER KIDS I CAN BE AS GOOD AS OTHER KIDS IF I WANT TO I AM JUST AS GOOD AS OTHER KIDS 
25. _ NOBODY REALLY LOVES ME

I AM NOT SURE IF ANYBODY LOVES ME

— I AM SURE THAT SOMEBODY LOVES ME

26. _ I USUALLY DO WHAT I AM TOLD I DO NOT DO WHAT I AM TOLD MOST TIMES I NEVER DO WHAT I AM TOLD

27. _ I GET ALONG WITH PEOPLE I GET INTO FIGHTS MANY TIMES

_ I I GET INTO FIGHTS ALL THE TIME 


\section{CURRICULUM VITAE}

Cristina T. del Busto

\section{EDUCATION}

Florida International University

Doctoral Candidate, Department of Psychology

Major Professor: Jeremy Pettit, Ph.D.

Expected date of completion: 2016

Florida International University

Degree: Master of Science, Department of Psychology

Major Professors: Jeremy Pettit, Ph.D., and Wendy K. Silverman, Ph.D.

Date of completion: August 2013

Florida State University

Degree: Bachelor of Science, Department of Psychology

Faculty Advisor: Janet Kistner, Ph.D.

Magna Cum Laude with Honors

Date of Completion: August 2009

\section{PUBLICATIONS AND PRESENTATIONS}

Marinez-Lora, A., Boustani, M., del Busto, C.T., Leone, C. Rusch, D., Frazier, S.L., \& Atkins, M. (accepted for publication 2016). An Iterative Framework for the Language Adaptation of an Intervention: Balancing Etic and Emic Perspectives. Hispanic Journal of Behavioral Sciences.

del Busto, C.T., Nichols-Lopez, K., Hernandez, I., Pettit, J.W., \& Silverman, W.K. (under review). Predictors of referral source for evidence-based treatment of anxiety in a sample of Hispanic-Latino children. Evidence Based Practice in Child and Adolescent Mental Health.

Miguel, E., Golik, A., del Busto, C.T., Comer, J.S., \& Furr, J.M. (October 2015). Selective Mutism in Multilingual and Language Minority Children. Poster presented at the Selective Mutism Group Annual Conference. Philadelphia, Pennsylvania.

Marin, C.E., del Busto, C.T., Rey, Y., Pettit, J.W., \& Silverman, W.K. (November, 2014). Latino Children with Selective Mutism or Social Anxiety Disorder: An Initial Examination of Cultural Factors. Symposium talk submitted for presentation at the biennial meeting of the National Latino Psychological Association, Albuquerque, NM. 
Marin, C.E., Rey, Y., Motoca, L., Pienkowski, M., Dahan, J., Hernandez, I., del Busto, C.T., \& Silverman, W.K. (March, 2014). Directionality of Peer Influence on Childhood Anxiety Treatment Outcome. Invited symposia to be presented at the annual Anxiety and Depression Conference. Chicago, Illinois.

del Busto, C.T., Rey, Y., Marin, C.E., Hernandez, I., Silverman, W.K. \& Pettit, J.W. (November 2013). Selective Mutism and Social Phobia: A first at look the cultural context in a clinic referred sample of anxious Hispanic children. Poster presentation at the Association for Behavioral and Cognitive Therapies Convention. Nashville, Tennessee.

del Busto, C.T., Hill, R., Rey, Y., Pienkowski, M., Dahan, J., Pettit, J. W. \& Silverman, W.K. (November 2013). Anxiety sensitivity and suicidal ideation in a clinic referred sample of anxious youth. Poster presentation at the Association for Behavioral and Cognitive Therapies Convention. Nashville, Tennessee.

Motoca, L. M., del Busto, C.T., Hedemann, E., Bechor, M., \& Silverman, W.K. (April 2013). The impact of parenting behaviors on child anxiety and avoidance in a clinic referred sample: An observational study. Symposium presented at the biennial meeting of the Society for Research in Child Development. Seattle, Washington.

Marin, C.E., del Busto, C.T., Rey, Y., \& Silverman, W.K. (October 2012). Anxiety Symptoms andits Correlates: A comparison between youth with Selective Mutism and youth with Social Phobia. Poster presented at the Selective Mutism Group Annual Conference. Orlando, Florida.

del Busto, C.T., Hernandez, I., \& Silverman, W.K. (November 2011). Examining culture as it relates to the clinical presentation of anxiety-disordered youth by referral source. Poster presented at the Association for Behavioral and Cognitive Therapies Convention. Toronto, Canada.

del Busto, C.T., Lopez, C.M., \& Kistner, J.A. (November, 2009). Are mothers biased in child ratings of depression and anxiety? Poster presented at the Association for Behavioral and Cognitive Therapies Convention. New York, NY.

del Busto, C.T., Lopez, C.M., \& Kistner, J.A. (April, 2009). Multiple informant agreement on comorbid symptoms of children referred for evaluation of ADHD. Talk given at the Annual Howard Baker Undergraduate Research Day, Department of Psychology, Florida State University, Tallahassee, FL. 